\title{
Novel GLIDES Technology for Grid Resiliency: Final Report
}

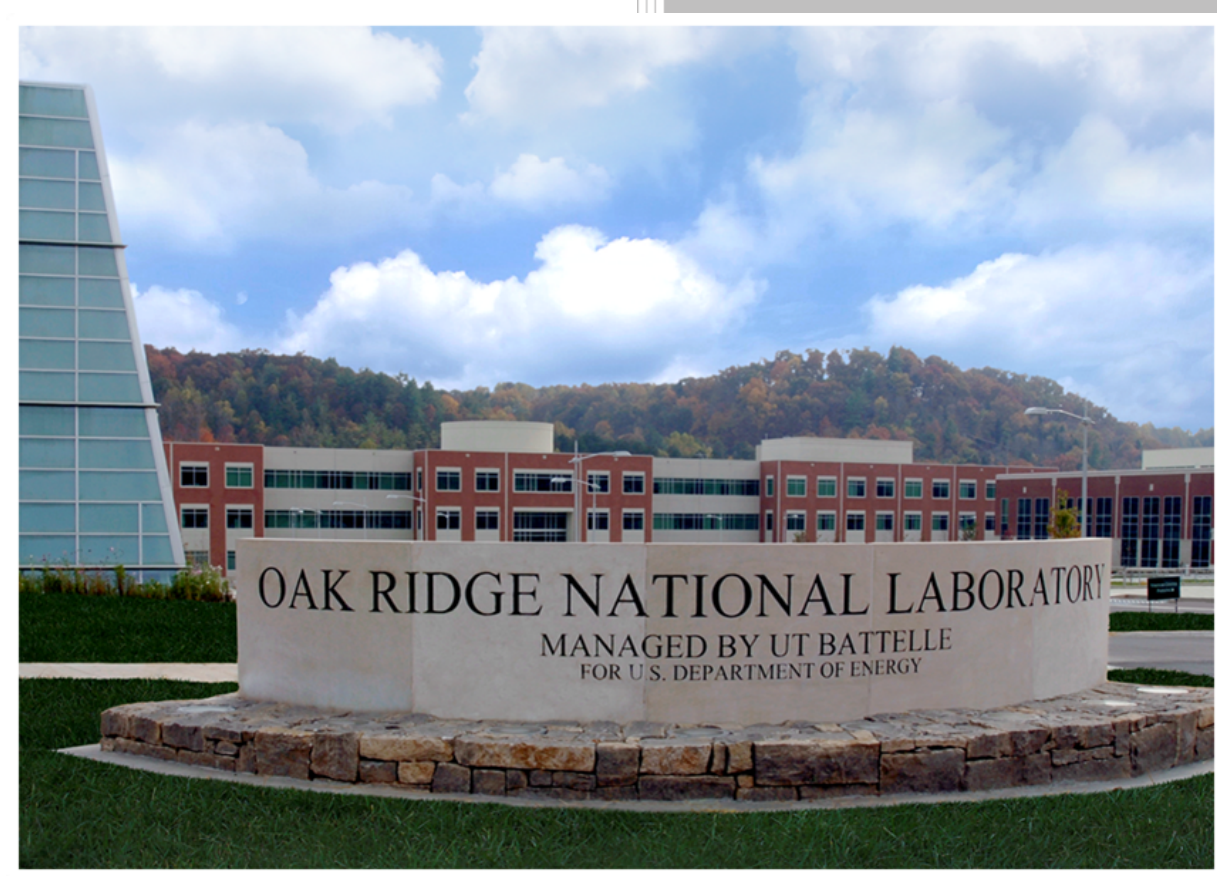

Ahmad Abuheiba

Saiid Kassaee

Praveen Cheekatamarla

Ayyoub Momen

$10 / 5 / 2020$ 


\title{
DOCUMENT AVAILABILITY
}

Reports produced after January 1, 1996, are generally available free via US Department of Energy (DOE) SciTech Connect.

Website www.osti.gov

Reports produced before January 1, 1996, may be purchased by members of the public from the following source:

\author{
National Technical Information Service \\ 5285 Port Royal Road \\ Springfield, VA 22161 \\ Telephone 703-605-6000 (1-800-553-6847) \\ TDD 703-487-4639 \\ Fax 703-605-6900 \\ E-mail info@ntis.gov \\ Website http://classic.ntis.gov/
}

Reports are available to DOE employees, DOE contractors, Energy Technology Data Exchange representatives, and International Nuclear Information System representatives from the following source:

Office of Scientific and Technical Information

PO Box 62

Oak Ridge, TN 37831

Telephone 865-576-8401

Fax 865-576-5728

E-mail reports@osti.gov

Website http://www.osti.gov/contact.html

This report was prepared as an account of work sponsored by an agency of the United States Government. Neither the United States Government nor any agency thereof, nor any of their employees, makes any warranty, express or implied, or assumes any legal liability or responsibility for the accuracy, completeness, or usefulness of any information, apparatus, product, or process disclosed, or represents that its use would not infringe privately owned rights. Reference herein to any specific commercial product, process, or service by trade name, trademark, manufacturer, or otherwise, does not necessarily constitute or imply its endorsement, recommendation, or favoring by the United States Government or any agency thereof. The views and opinions of authors expressed herein do not necessarily state or reflect those of the United States Government or any agency thereof. 
Electrification and Energy Infrastructure

\title{
Novel GLIDES Technology for Grid Resiliency
}

\author{
Ahmad Abuheiba \\ Saiid Kassaee \\ Praveen Cheekatamarla \\ Ayyoub Momen
}

Date Published:

October $5^{\text {th }}, 2020$

Prepared by

OAK RIDGE NATIONAL LABORATORY

Oak Ridge, TN 37831-6283

managed by

UT-BATTELLE, LLC

for the

US DEPARTMENT OF ENERGY

under contract DE-AC05-00OR22725 



\section{CONTENTS}

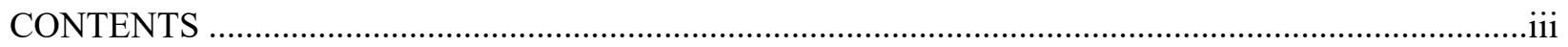

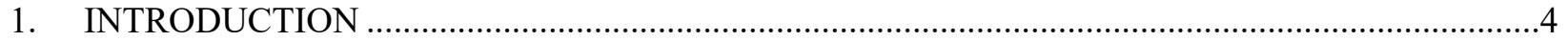

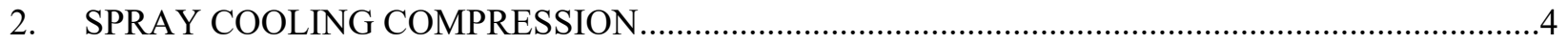

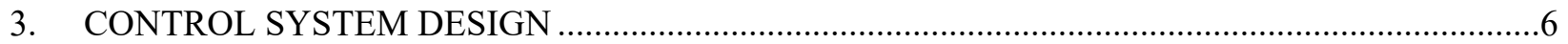

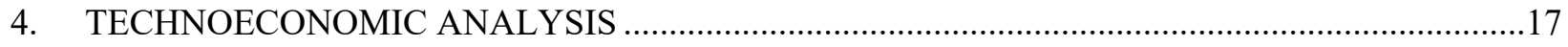

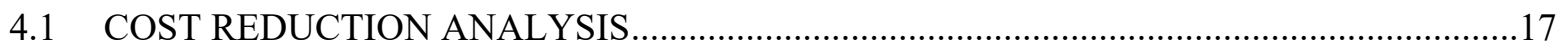

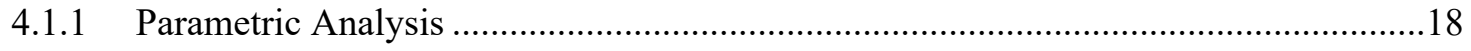

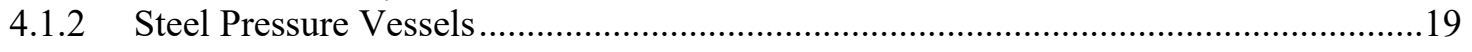

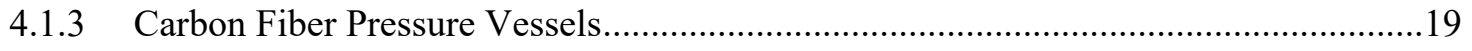

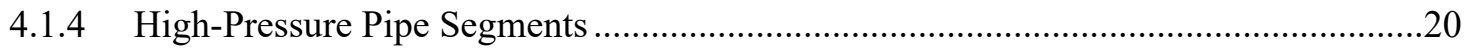

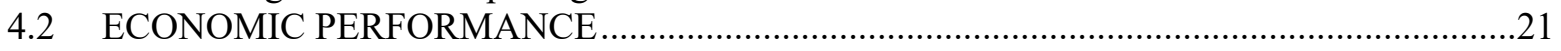

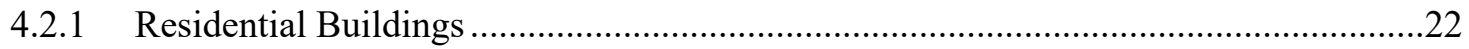

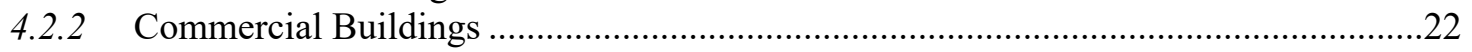

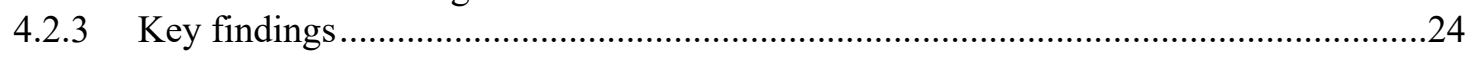

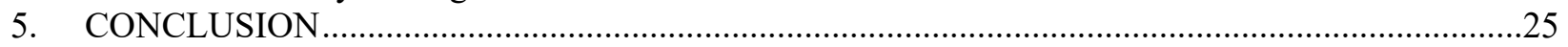




\section{INTRODUCTION}

The transformative Ground Level Integrated Diverse Energy Storage (GLIDES) technology was invented and had early stage success demonstrated at Oak Ridge National Laboratory (ORNL) in 2013-2017. The first proof-of-concept demonstration prototype of GLIDES has been successfully developed. In May 2016, this unique technology was a featured story in the ASHRAE newsletter. ${ }^{1}$ A detailed thermophysical analysis of this system has also been already published [1-4].

GLIDES stores energy by compressing gas in high-pressure vessels. However, unlike most gas compression schemes, it does not use a low-efficiency gas compressor. Instead, electricity (e.g., from offpeak grid or renewable sources) runs a high-efficiency hydraulic pump and pumps water against air inside the vessels. During air compression, water could be sprayed into the top of the vessel to keep the air temperature constant to achieve near isothermal compression (thermodynamically, the best possible compression process) and reduces the compression work by $30 \%$ compared with conventional adiabatic compression. When electricity is required, the high-pressure gas pushes liquid from the pressure tank through a prime mover coupled to a generator to generate electricity. Prototype measured data, as well as the thermodynamic analysis, suggest this transformative technology will significantly outperform leadacid batteries and provide a round trip efficiency (RTE) of $70-82 \%$ at a storage cost of $<\$ 180-400 / \mathrm{kWh}$ (half that of lead-acid batteries).

To bring industry acceptance of the technology, the current research focus of the GLIDES system is to make the technology ready for grid. To do so, the project identified the following objectives:

1. Spray cooling to improve both RTE and energy density (ED)

2. Design load following control system

3. Perform technoeconomic analysis to quantify GLIDES value proposition

\section{SPRAY COOLING COMPRESSION}

Expansion and compression losses are the only losses that are not machinery-loss as shown in Figure 1. That means that these losses cannot be reduced by simply choosing higher efficiency machinery (e.g. motor, or pump). Rather, these losses are caused by the rise/drop of air temperature as it compresses/expands. During charging, the temperature of the air rises due to the compression work. The rise in temperature causes a rise in the pressure of the air. The pressure rises to the maximum allowable working pressure of the vessels at less water volume than the possible maximum volume. The maximum possible volume is when the compression process takes place with no rise in temperature, i.e. isothermal compression.

\footnotetext{
${ }^{1}$ ASHRAE-The HVAC\&R Industry, Newsletter, May 5, 2016, Vol 15, No. 17: https://www.ashrae.org/resources--publications/periodicals/enewsletters/eindustry/hvac-rindustry-2016-05-05
} 


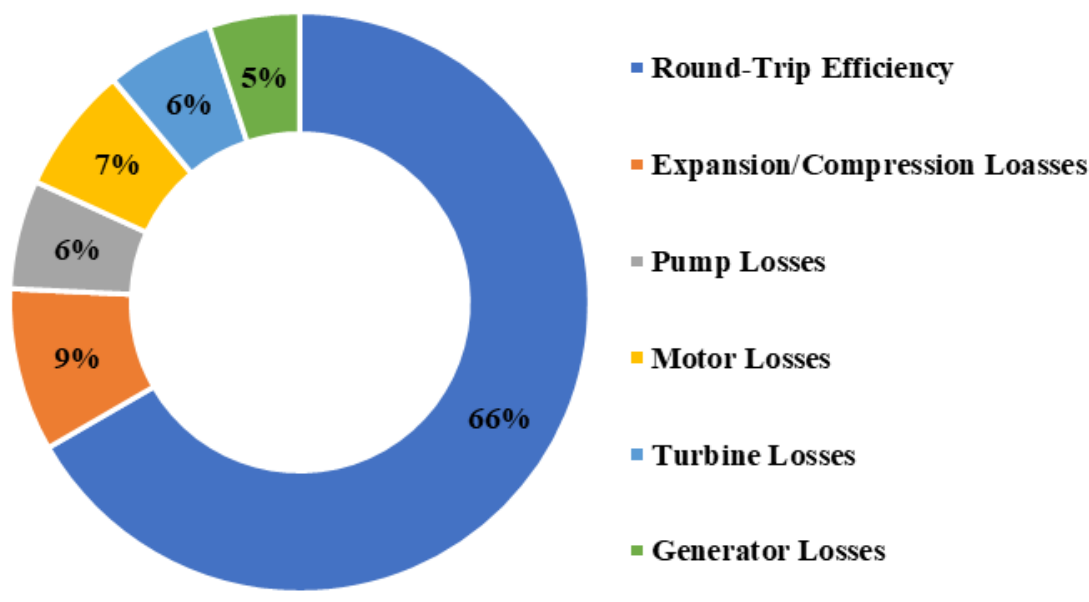

Figure 1. Itemized efficiency losses in baseline GLIDES system. Reproduced from data in [1]

To reduce the rise in air temperature during the charging process, the system was charged from the top of the pressure vessel using a spray nozzle as shown in Figure 2. With water being sprayed into the top of the pressure vessel, the process will be very close to an isothermal process with less than $5^{\circ} \mathrm{C}$ temperature change during charging. The $\mathrm{P}-\mathrm{V}$ diagram of the charging process is shown in Figure 3 comparing the experimental data with isothermal and adiabatic processes.

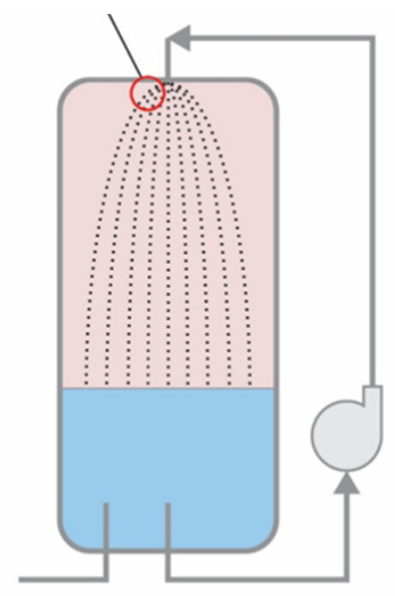

Figure 2. Spray cooling/heating in GLIDES. 


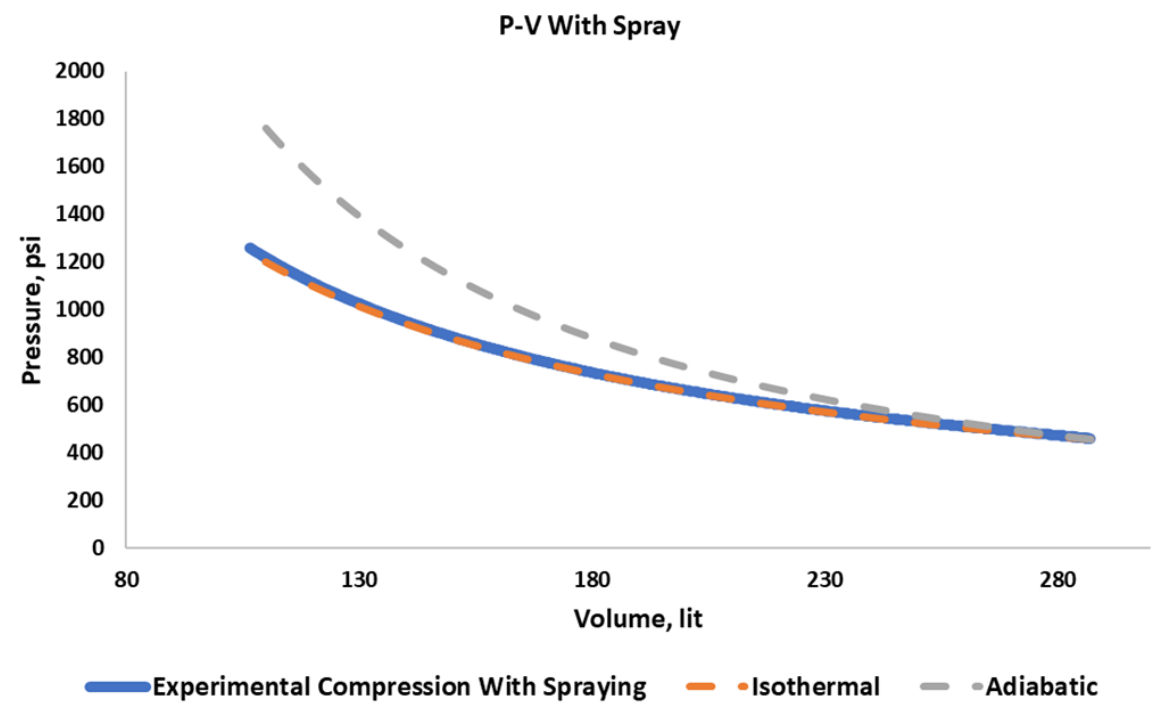

Figure 3. GLIDES charging process P-V diagram

Plotting the logarithmic P-V diagram of the experimental data shows a polytropic coefficient of 1.01 (isothermal $=1$ ), compared to 1.2 when not using spray charging. The isothermal compression results in utilization of more of the volume of the vessel, resulting in $12 \%$ increase in energy density of GLIDES compared to the baseline case (without spray). This translates into $11 \%$ reduction in the cost per kWh of GLIDES.

\section{CONTROL SYSTEM DESIGN}

To design a load following control system for the GLIDES system, it was needed to better characterize the power output under varying load. To emulate a load, a new load bank with 2 discreet load levels was built and added to GLIDES. Figure 4 and Figure 5 show GLIDES load schematic and their integration with the generator respectively. On each phase, two incandescent bulbs were added for a total of 6 light bulbs. These 6 bulbs were grouped into two groups. Every 3 bulbs, one on each phase, are activated by a single relay. A 3-phase variable output transformer (VARIAC) is installed between the entire load bank and the generator. This arrangement provides us with flexibility to characterize the performance in different modes: maximum power tracking, load following or constant frequency. The GLIDES supervisory control system is programmed to respond to the operational mode by changing the load (how many relays are closed) based on the rpm of the generator, the voltage and the current of the load. The updated load bank schematic including 3 voltage transducers, a frequency transducer, 3 current transducers, and a power transducer is shown in Figure 6. 


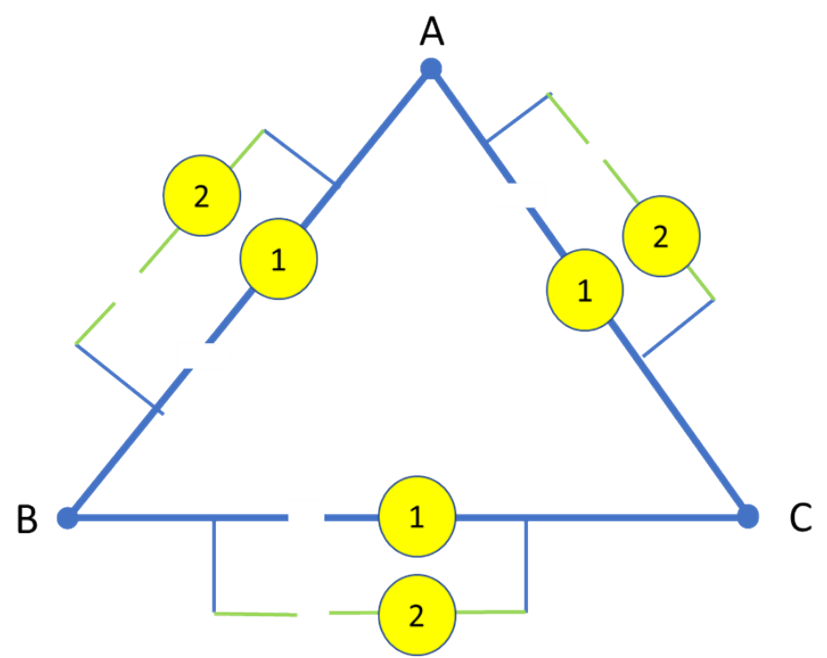

Figure 4. GLIDES generator Load Distribution.

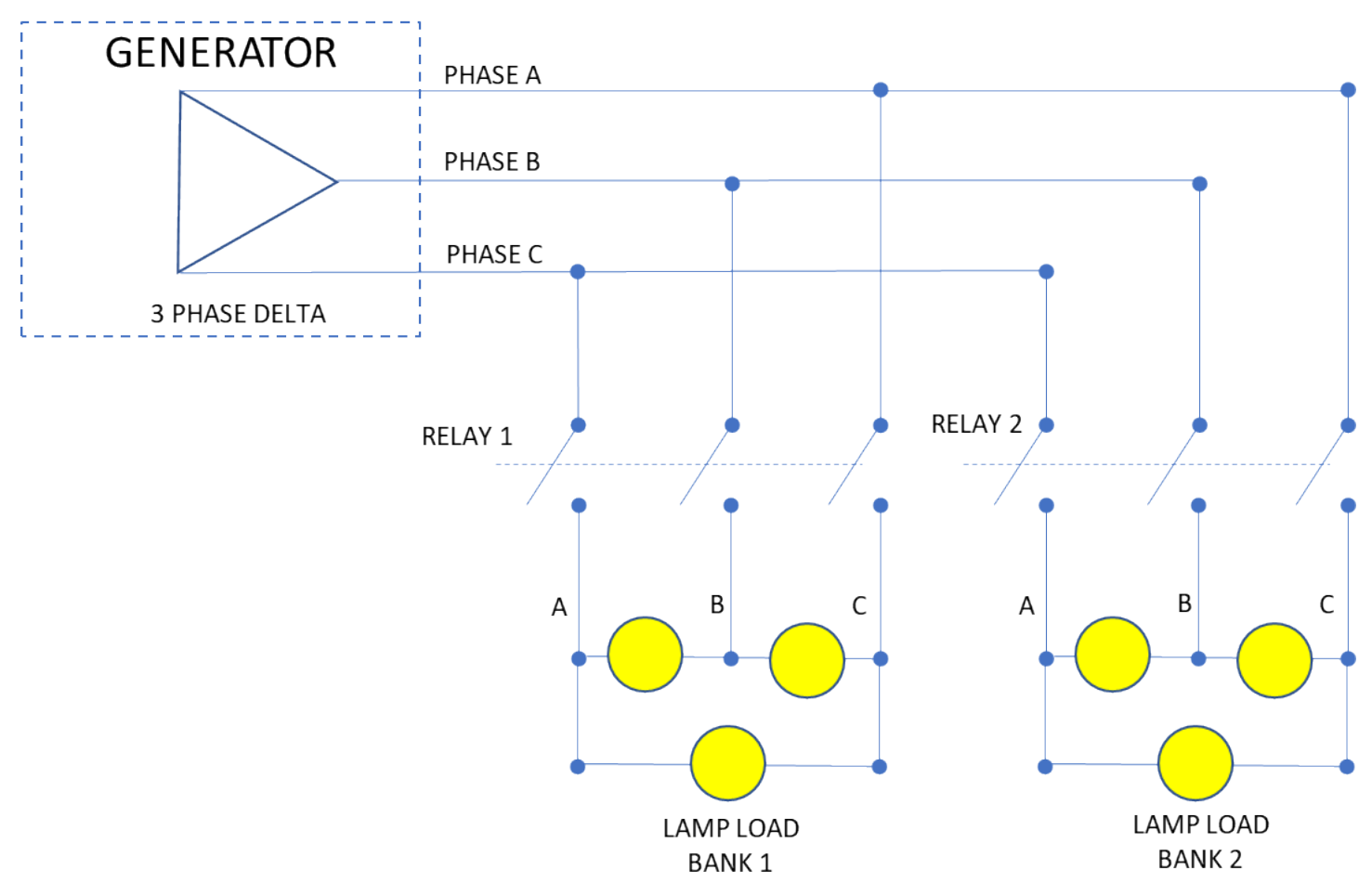

Figure 5. GLIDES Load Distribution \& generator layout schematic 


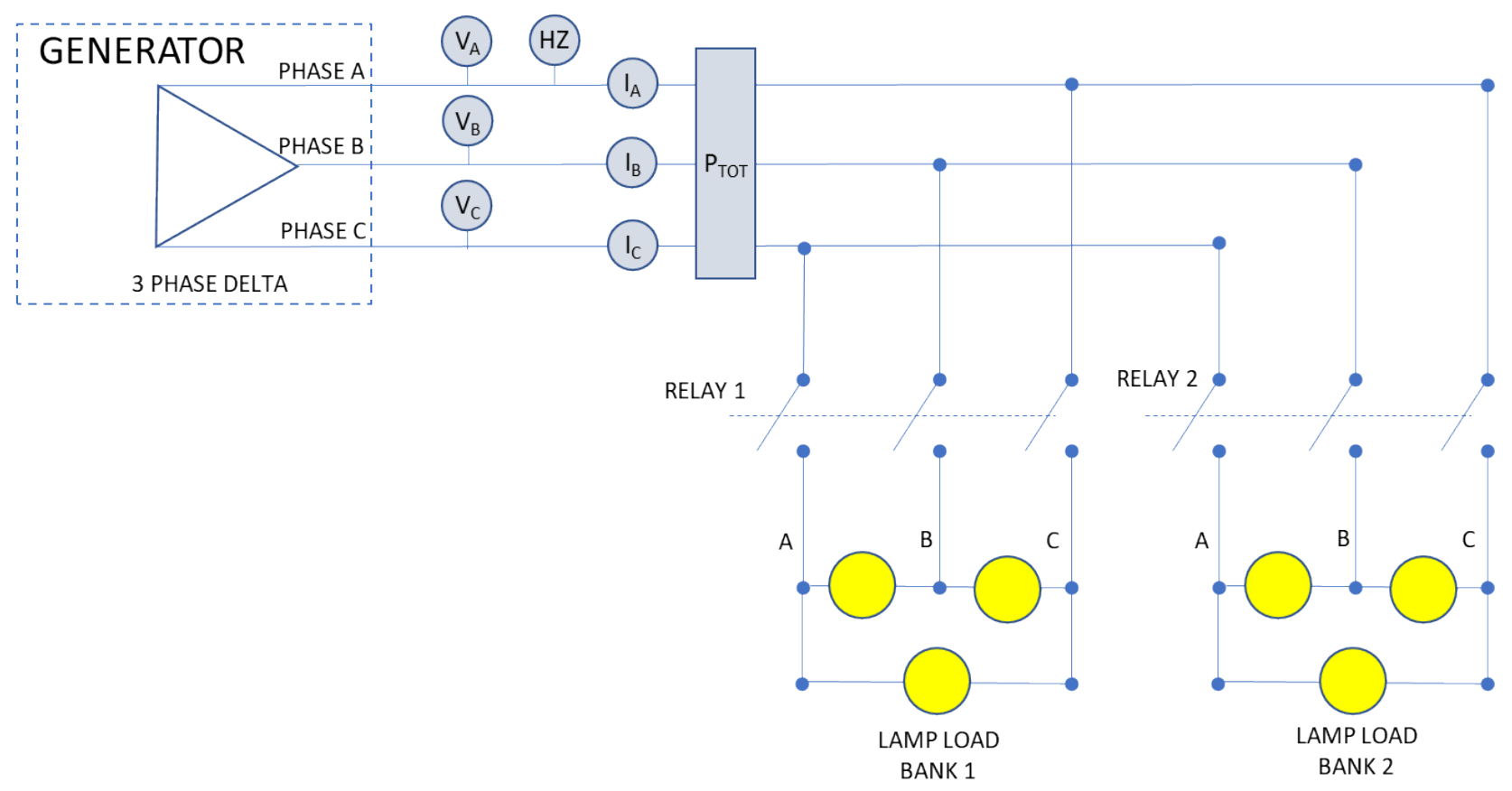

Figure 6, GLIDES Load Distribution and Generator Layout Schematic Including Added Transducers.

Eight transducers were installed on the GLIDES system including a watt/watt-hour transducer, three voltage RMS transducers, three current transducers, and a frequency transducer. These additional transducers were added to an ICDP data acquisition module that was connected to the ORNL network for ease of data acquiring. As shown in Figure 7, during previous runs of the GLIDES system, a Variac was used to keep the RPM constant during the discharge process. To monitor the profiles mentioned above, the output load of the system was connected directly to the transducers installed, and from there to the Variac and to the load decreasing inaccuracy in data recorded. The Variac was used during the beginning of this operation to control the initial RPM, but was not used to keep the RPM constant, as done previously, to be able to study the behavior of the mentioned parameters with the changes in pressure profile. 

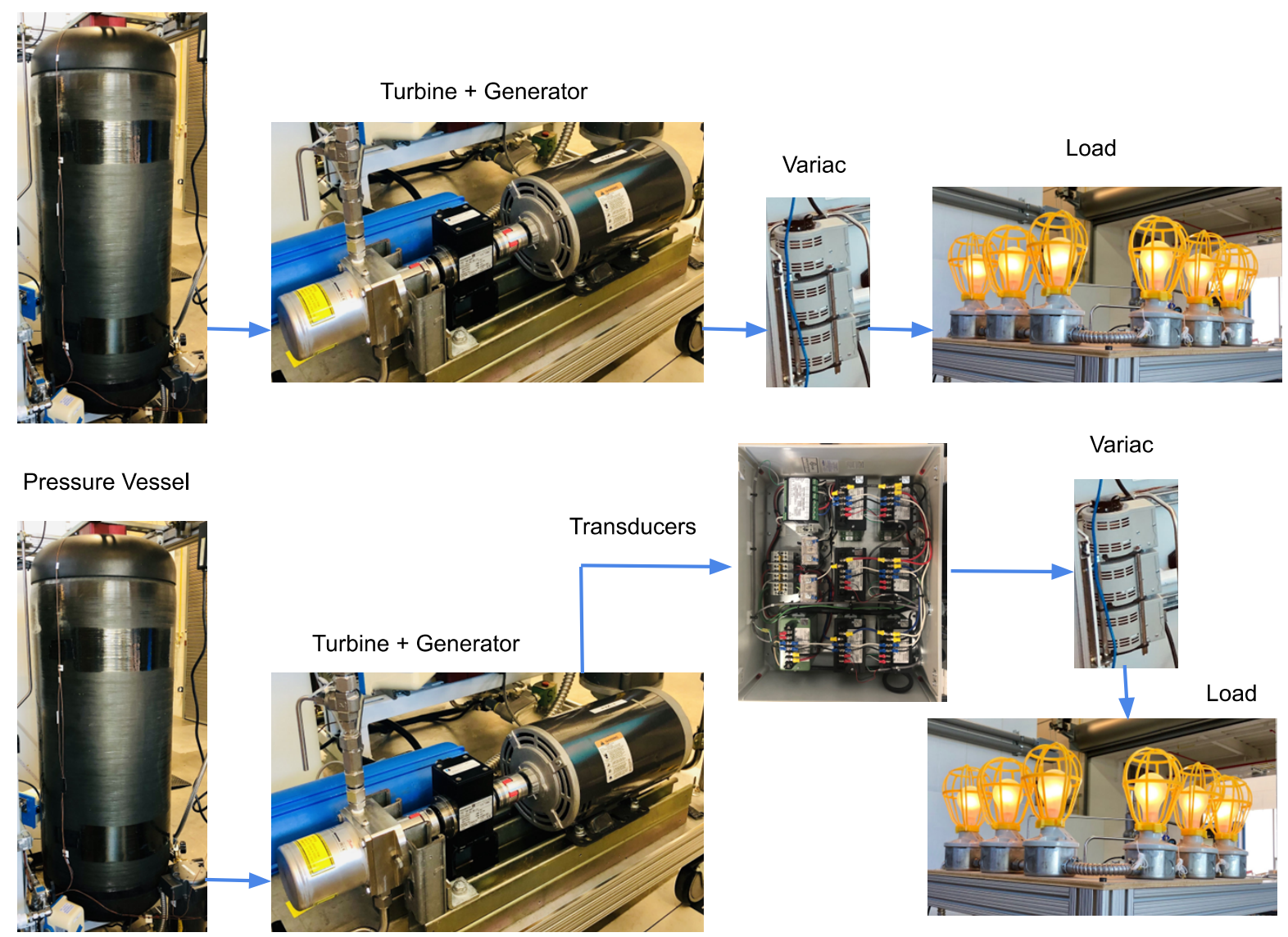

Figure 7, GLIDES second prototype with added transducers

The GLIDES system was run to collect the power output data; as this study was on the load following capabilities, only the discharging data were studied. The following plots show the gathered data.

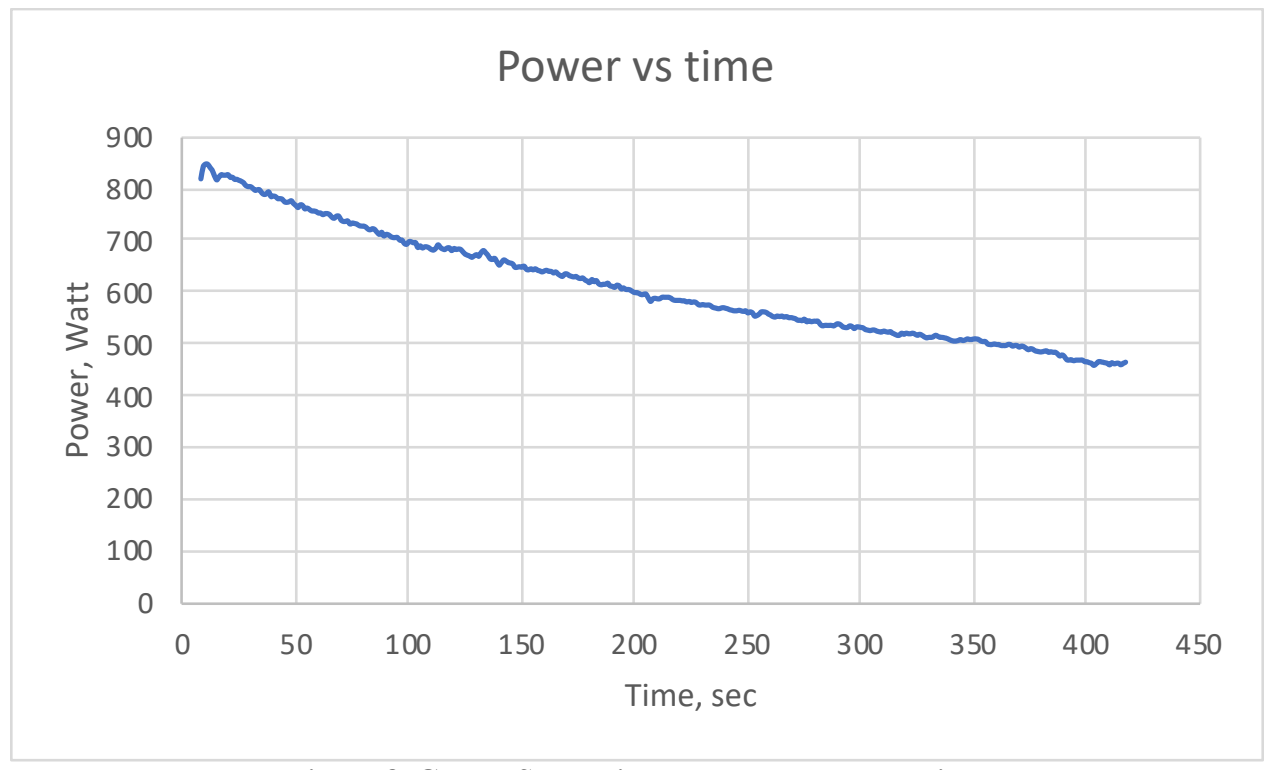

Figure 8, GLIDES experimental data, power vs time 


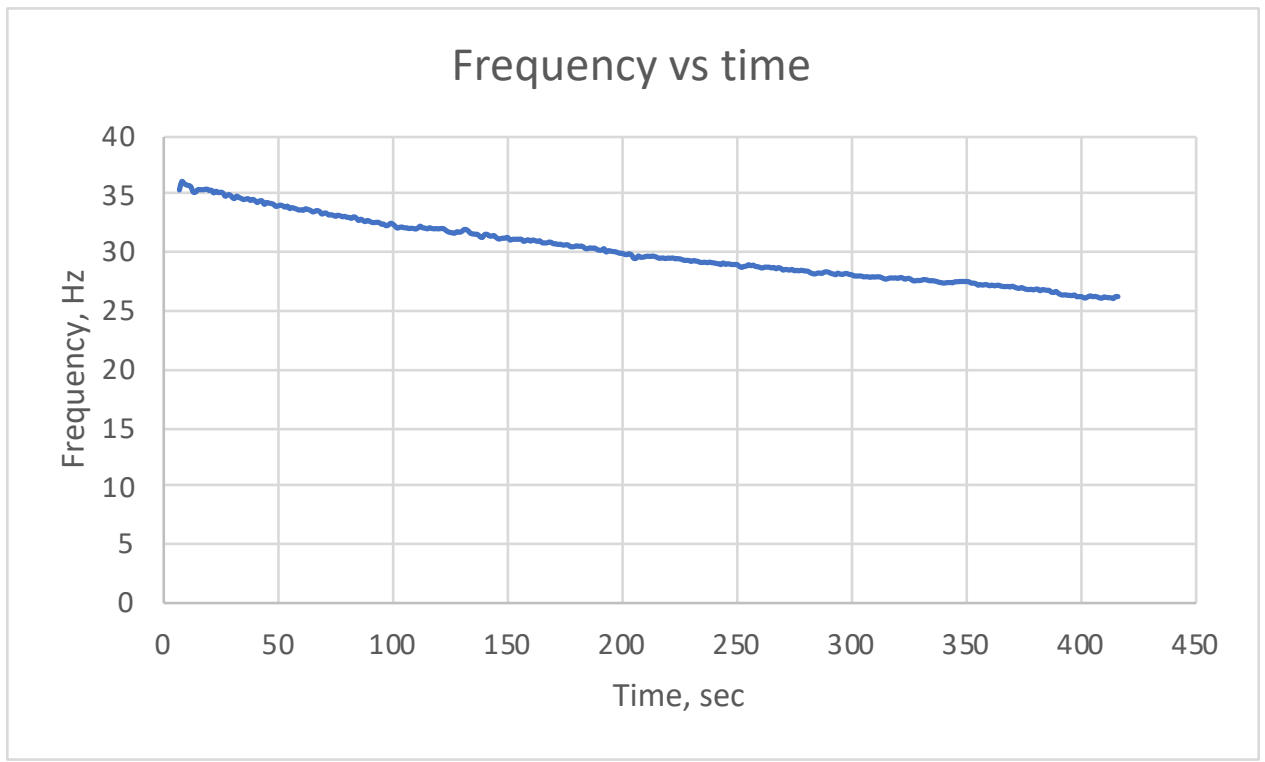

Figure 9, GLIDES experimental data, frequency vs time

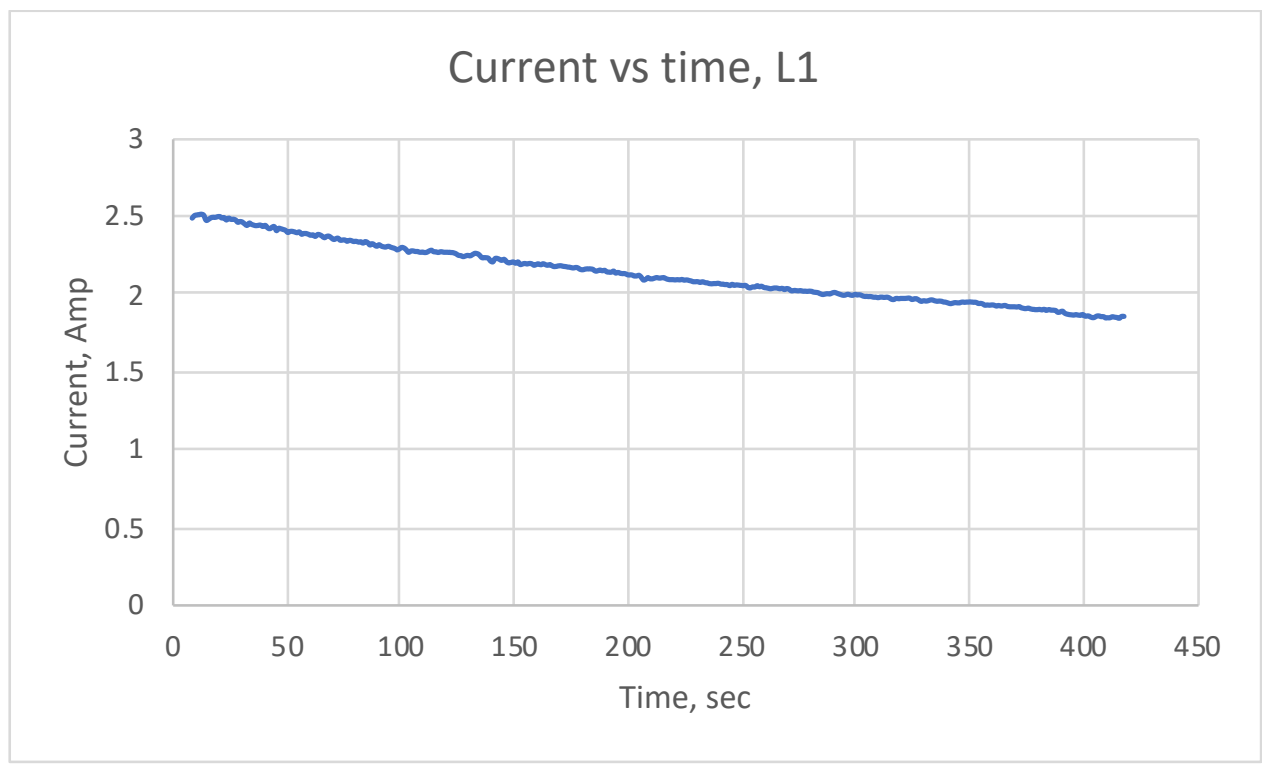

Figure 10, GLIDES experimental data, current vs time, L1 


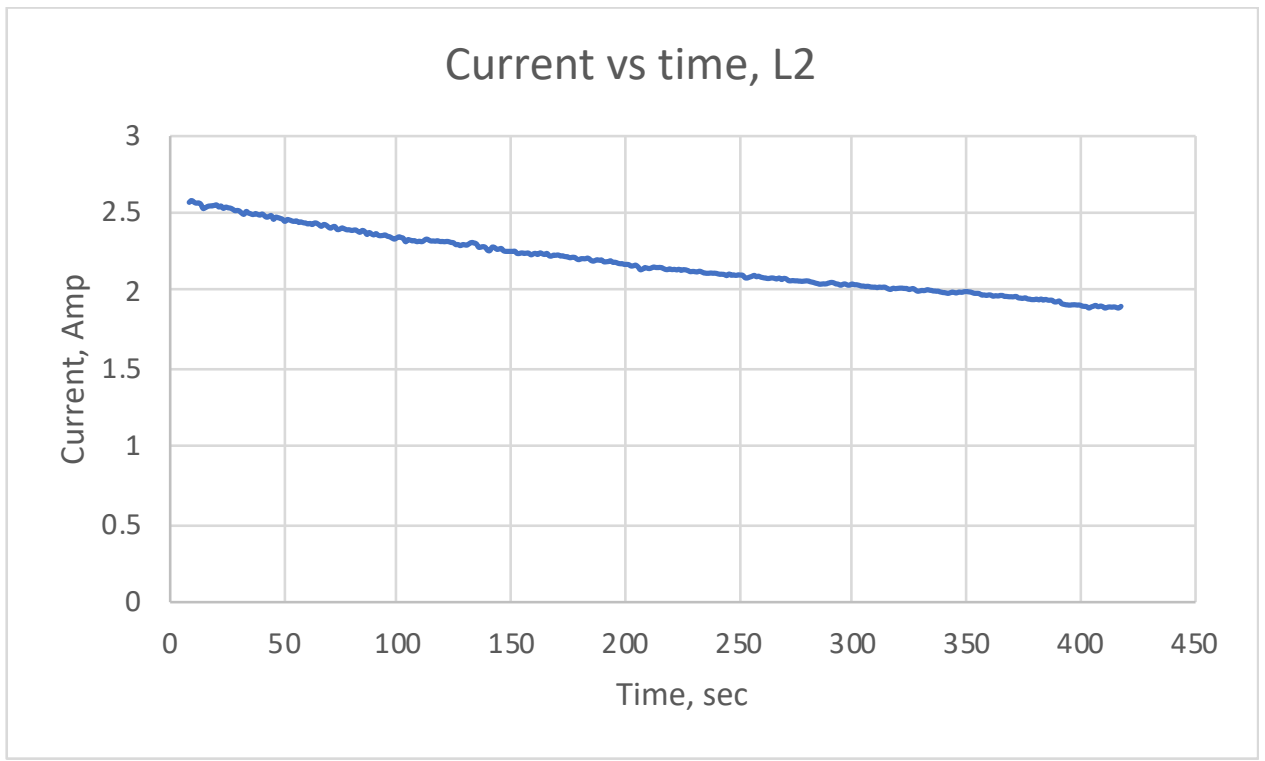

Figure 11, GLIDES experimental data, current vs time, L2

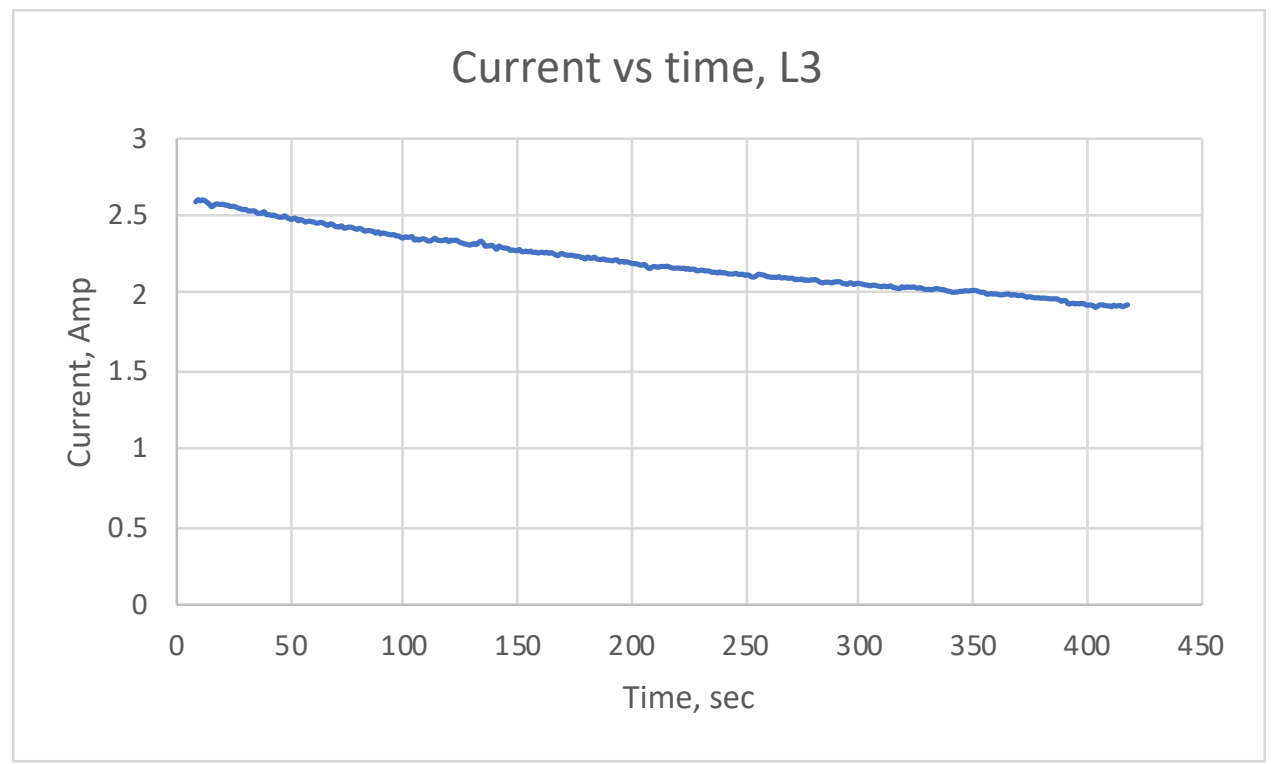

Figure 12, GLIDES experimental data, current vs time, L3 


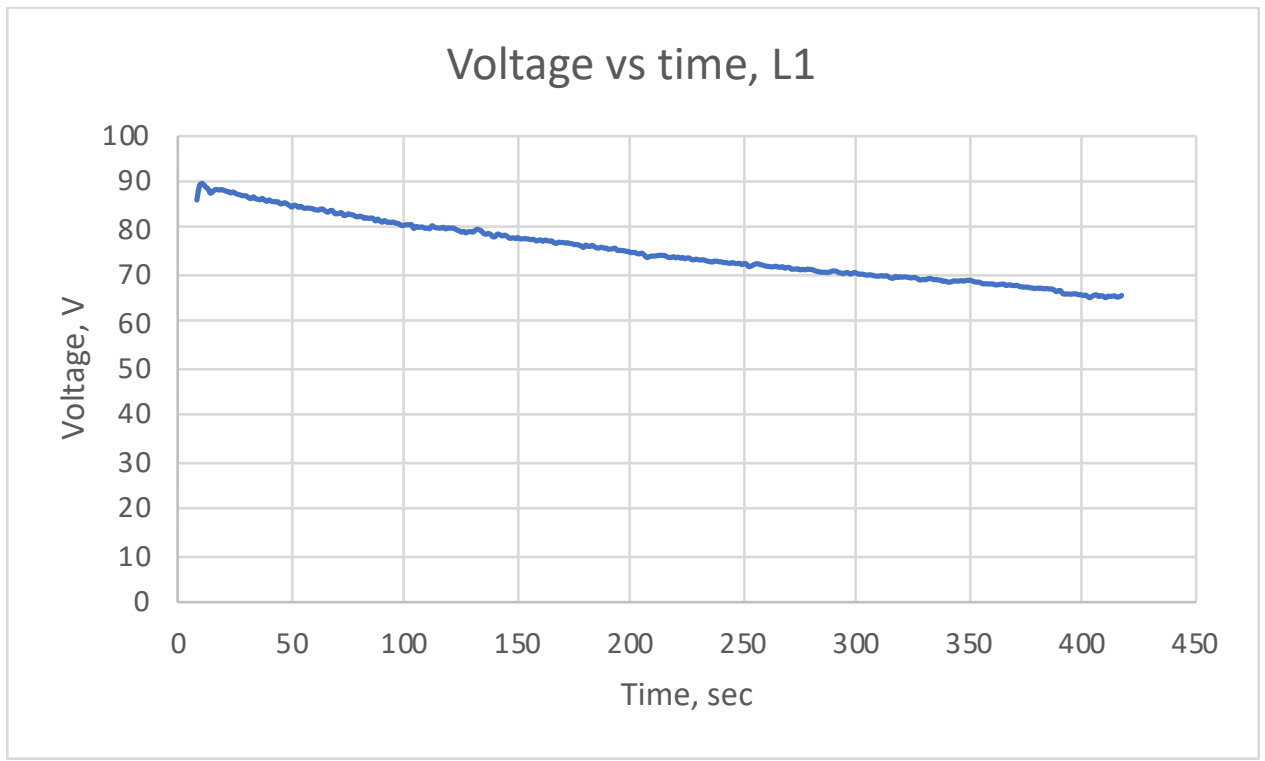

Figure 13, GLIDES experimental data, voltage vs time, L1

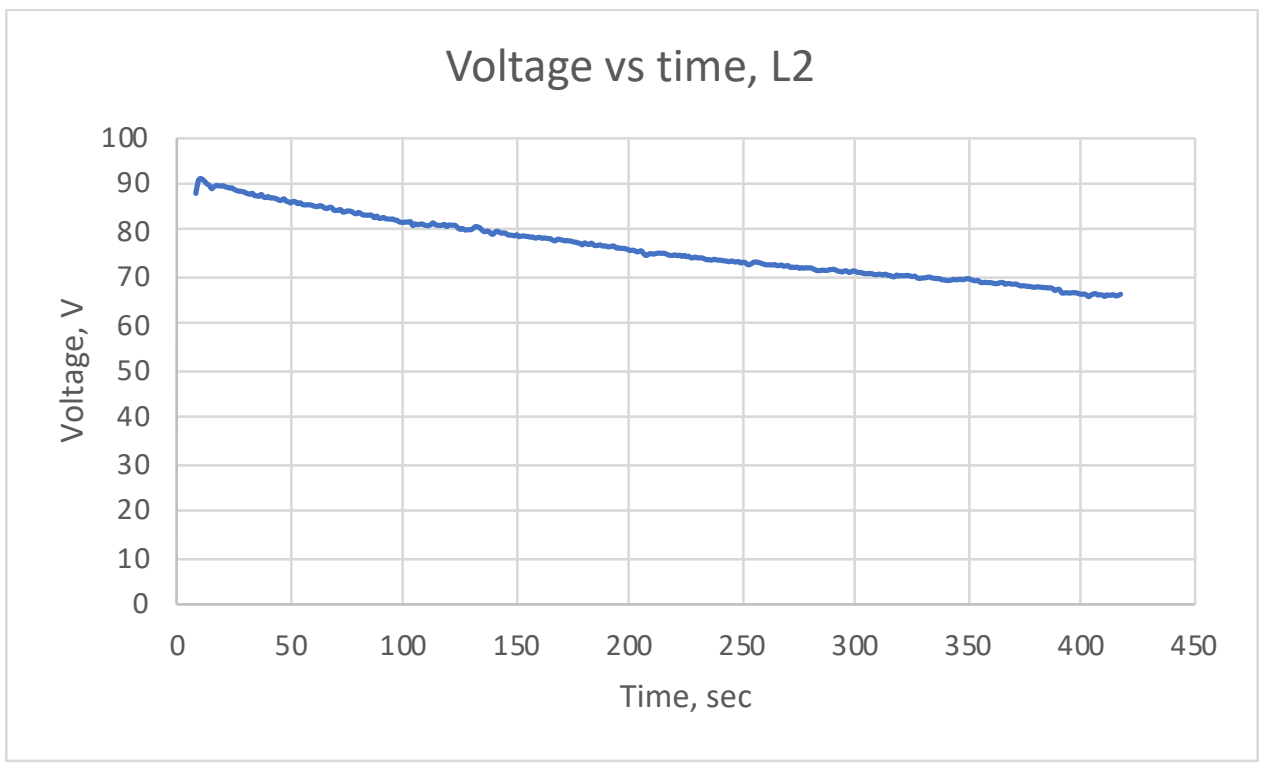

Figure 14, GLIDES experimental data, voltage vs time, L2 


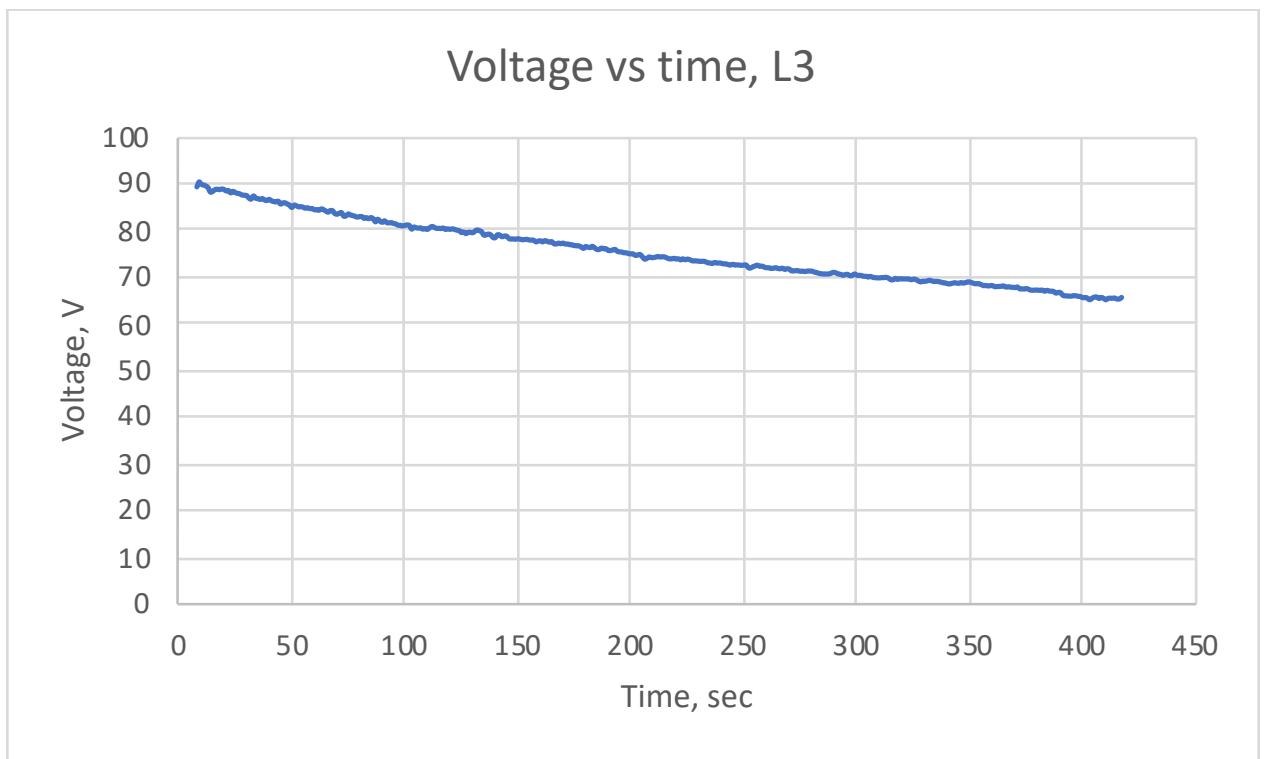

Figure 15, GLIDES experimental data, voltage vs time, L3

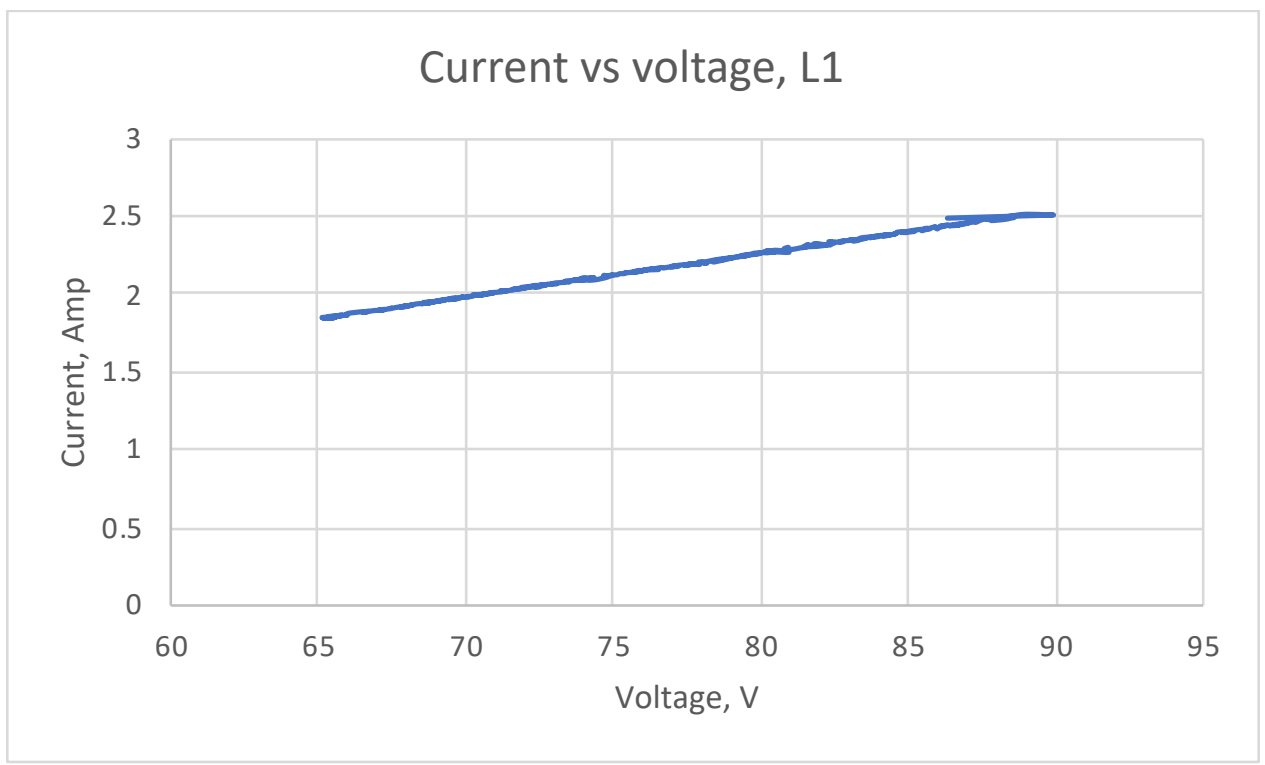

Figure 16, GLIDES experimental data, current vs voltage, L1 


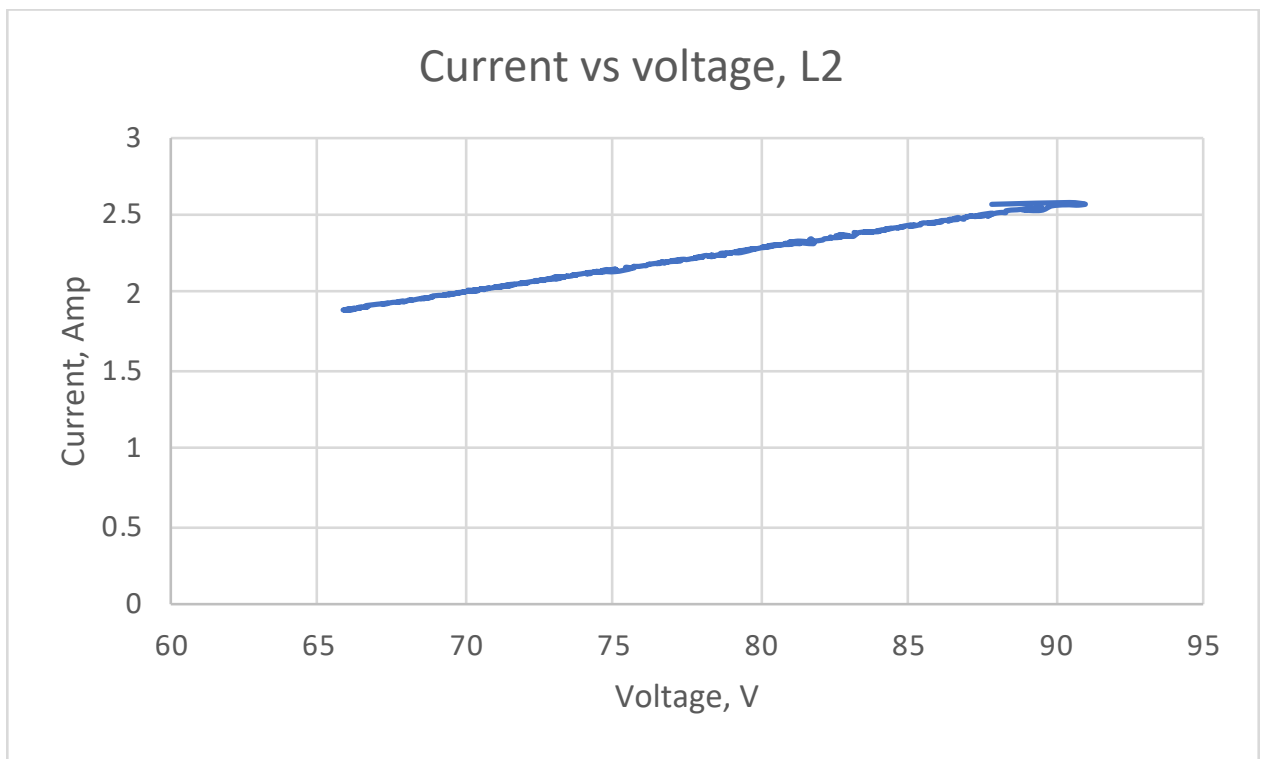

Figure 17, GLIDES experimental data, current vs voltage, L2

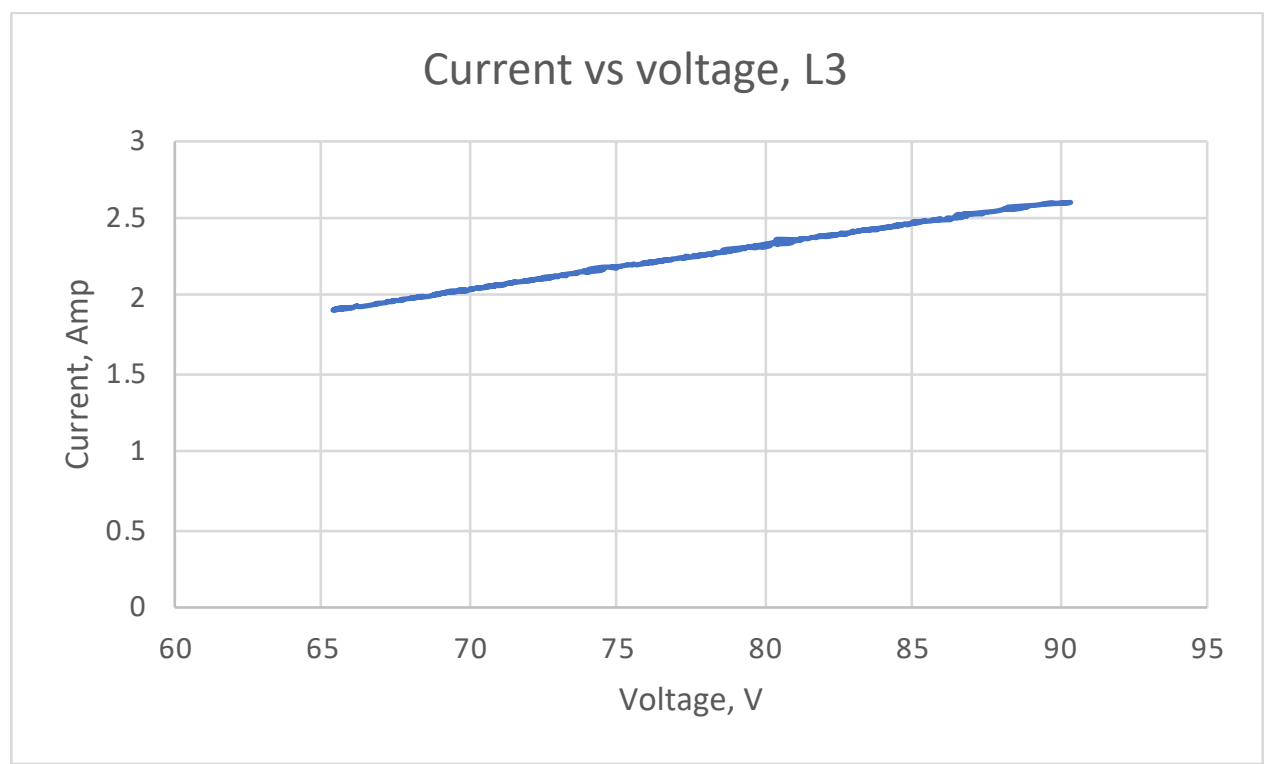

Figure 18, GLIDES experimental data, current vs voltage, $L 3$

The following empirical correlations have been developed from the experimental data:

$$
\begin{gathered}
f=R P M / 30 \\
V=R P M / 12 \\
I=0.0284 \times V \\
\tau=1.5619 \times I
\end{gathered}
$$

Where $f$ is the frequency (HZ), $R P M$ is the speed at which the generator is running, $\mathrm{V}$ is the generator phase voltage $(\mathrm{V}), I$ is the generator line current $(\mathrm{A})$, and $\tau$ is the mechanical torque $(\mathrm{Nm})$. 
Since the initial target application is 'behind the meter' residential, voltages for interconnection are 120 $\mathrm{V}_{\mathrm{RMS}} / 240 \mathrm{~V}_{\mathrm{RMS}}$ for most single-family homes. $240 \mathrm{~V}_{\mathrm{RMS}}$ interconnection of energy storage is preferred, as this provides a natural balance of supply to a home (since residential is often split into multiple $120 \mathrm{~V}$ feeds from the $240 \mathrm{~V}$.) To meet a full house voltage $\left(240 \mathrm{~V}_{\mathrm{RMS}}\right.$ single phase $/ 240$ split phase), a DC voltage range of approximately $400 \mathrm{~V}$ nominal is needed. For $120 \mathrm{~V}_{\mathrm{RMS}}$, the voltage can be significantly lower, but may have restrictions on building integration. Figure 19 shows the different possible topologies for the control system.

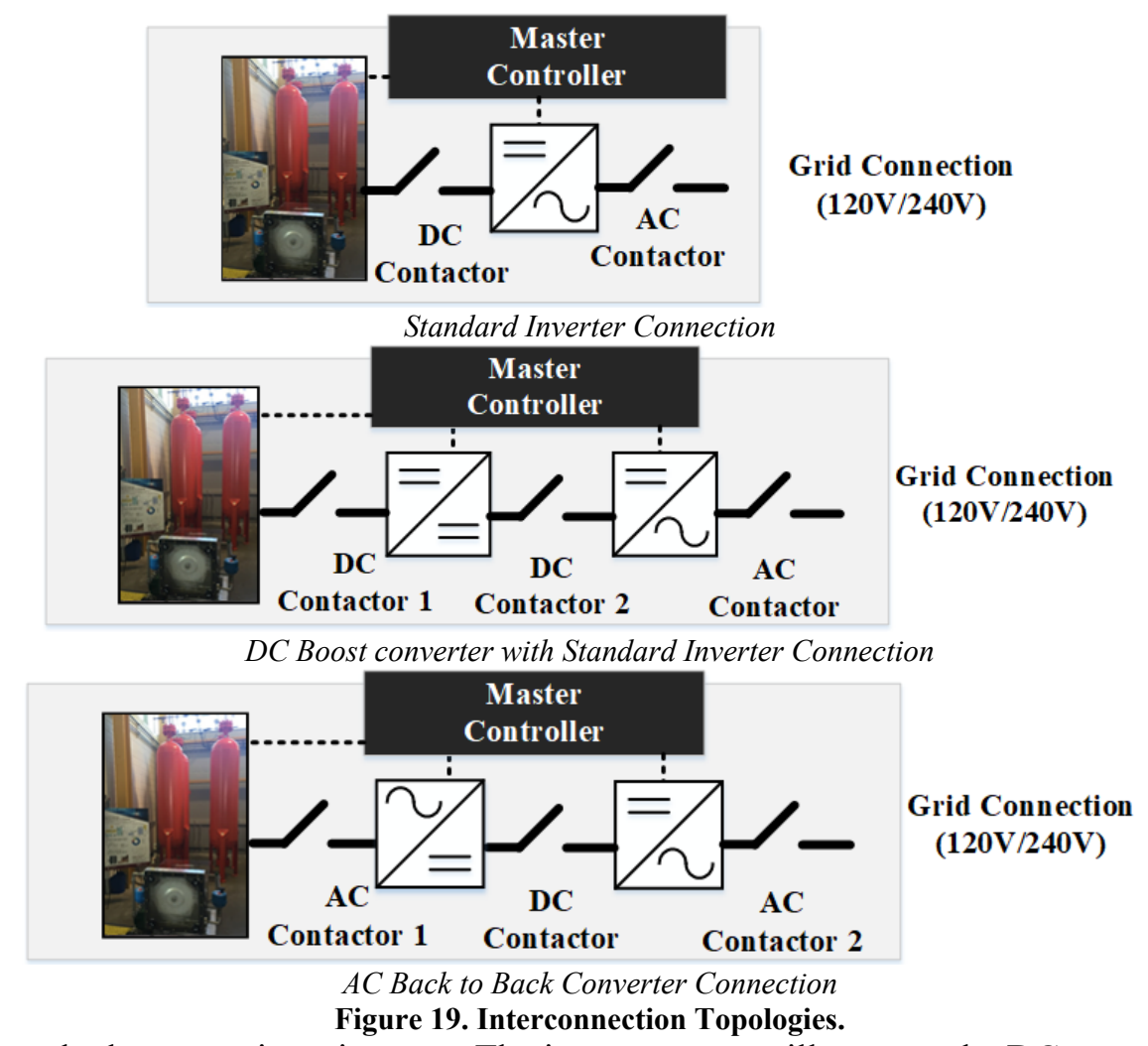

In all topologies, the last stage is an inverter. The inverter stage will convert the DC output to AC through Pulse Width Modulation (PWM) switching of different power electronic modules. This will require a digital signal processor (DSP) that can phase-lock-loop with the electric grid connection and inject current (or power) based on the grid reference. Several safety measures and protection measures should be on this inverter including automatic fault, over and under current, and over and under voltage detection and interruption. These safety features must be programmed on the DSP to ensure immediate response.

Contactors are shown to achieve the needed isolation between different stages of the system. Software within a master controller will need to address the stages of control and contactor engagement to support integration of these sub-systems. As an example, a master computer, depending on the required decision making, could be a Raspberry Pi and support the communication and hosting of different key services as shown in Figure 20. A critical component to ensuring full system operation is the continuous coordination between the GLIDES system and the power converters as well as the contactors. This coordination is extracted to a higher level via commands such as 'start-up' and 'shut-down' that are derived from an outside controller through the Systems Interface or 'error' which can be sent from the sub-systems. 


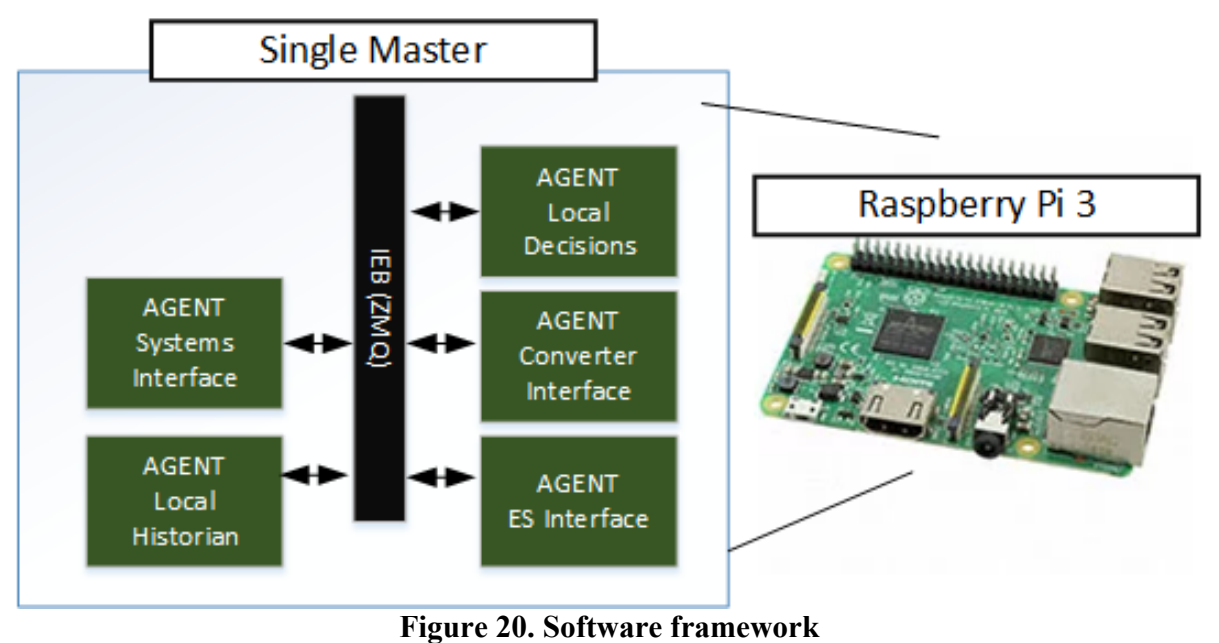

To test the full system implementation, multiple options under were examined: 1) Interconnect to ORNL electric system development testbed at NTRC (Figure 20) and 2) Interconnect to ORNL test-house located at Yarnell Station (Figure 21). The initial NTRC connection provides the most comprehensive and flexibility as the system can be constructed and tested for initial interoperability while providing additional isolation from the grid. NTRC I has multiple Amtek grid emulators that provide a grid reference and are able to charge and discharge to an electric grid based on the connected system. With the Amtek, different voltage magnitudes can be created that allow early functionality testing of the system reducing the likelihood of system complete system failure. The Amtek supports automatic fault protection in case of electric interconnection failure of the energy storage technology.

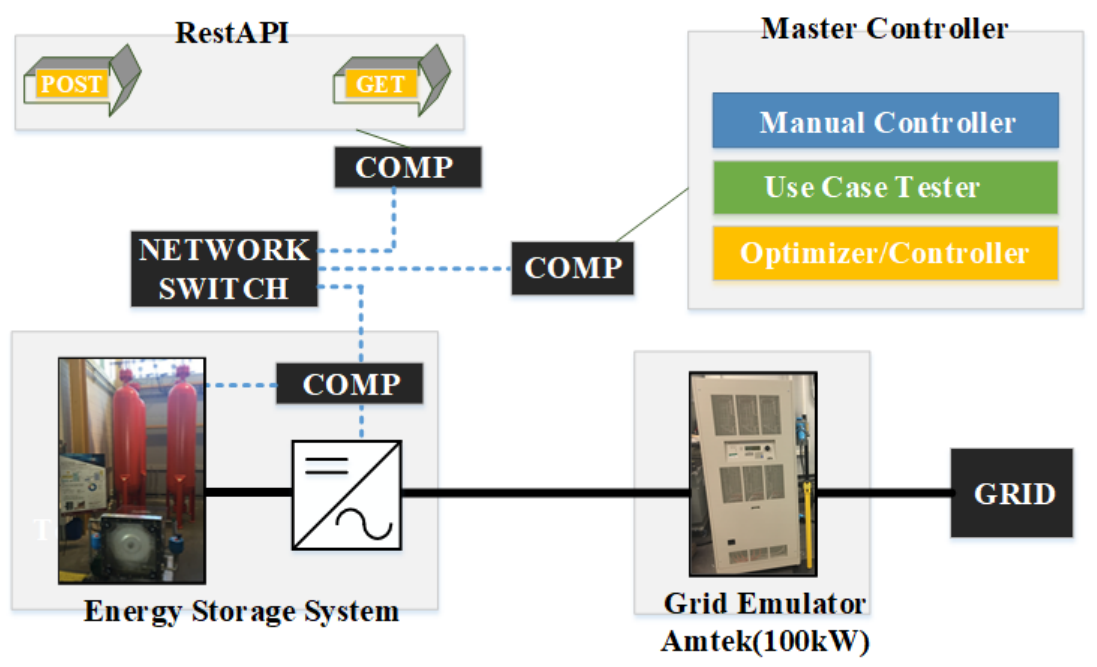

Figure 21. Systems Integration at the National Transportation Research Center, Building I

Furthermore, initial development is free from weather environments such as precipitation and temperature that might impact development and operations. As shown, the network switch with application programming interface (API) can provide a communication to a exterior system that provide the flexibility to manual dispatch and confirm functionality, run various optimization case scenarios, or use cases that have been standardized by the Department of Energy, Energy Storage Program. Integration in Yarnell Station test house will require additional incorporation of electrical infrastructure, including a potential concrete pad for setting the system, conduit to run the appropriate electrical and communication lines, and 
electrical panel to support the integration into the building and provide isolation. This can include the final demonstration phase of the project with climate and precipitation testing.

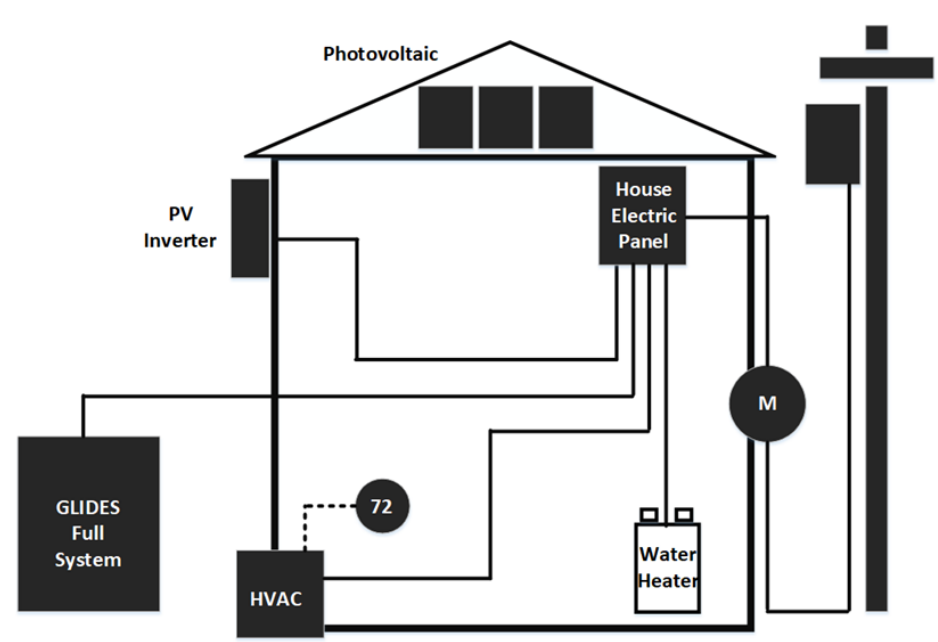

Figure 22 Implementation of GLIDES at Yarnell Station Test house.

It was decided that the integration of GLIDES would better be done at NTRC. However, the integration was not completed in FY20 due to re-organization of the space at NTRC.

\section{TECHNOECONOMIC ANALYSIS}

\subsection{COST REDUCTION ANALYSIS}

Energy storage systems, depending on their scalability, can be used in both household and grid applications. To analyze the cost and performance of GLIDES for these two applications, a technoeconomic model was developed which consists of a physics-based performance model combined with a cost model with the goal to maximize system efficiency with the lowest cost $\$ / \mathrm{kWh}$. This model was used to size a storage system with steel pressure vessels, carbon fiber pressure vessels, and high-pressure pipe segments for system capacities ranging from $10 \mathrm{~kW}$ (close to Tesla's Powerwall) to $300 \mathrm{MW}$ (close to that of a CAES plant). These systems were sized for storage hours ranging from 2 to 6 hours and pressure ratios ranging from 1.3 to 20 .

To compare the costs associated with the systems using steel vessels, carbon fiber pressure vessels, and high-pressure pipe segments, a cost analysis model was developed using the MATLAB programing package. The cost analysis model is an optimization model that solves for the lowest $\$ / k W h$ system cost based on steel and carbon fiber pressure vessels and high-pressure pipe segments cost data gathered from manufacturers to build the desired GLIDES system size. The model takes the desired system size $(\mathrm{kWh})$, an estimated roundtrip efficiency value, a pressure ratio ( $\mathrm{max} / \mathrm{min}$ pressure), and the pressure reservoir data (diameter, height, volume, maximum pressure, and price per vessel) from the manufacturers as the input. Using these inputs, based on the boundary work relation in a polytropic process $\left(W_{b}=\int_{1}^{2} P d V, P=C V^{n}\right)$ the amount of energy which can be stored per unit volume is calculated using Eq. $\left(E_{s t}=\frac{p_{\max }\left(\frac{p_{\max }}{p_{\min }}\right)^{-\frac{1}{n}}-p_{\min }}{1-n}\right.$

(5). It then solves for the total storage volume needed based on the total energy storage needed and the desired system capacity $(\mathrm{kWh})$ 
using Eq. $\left(V_{s t}=\frac{\text { Rated Power } \times \text { storage time }}{\eta_{R T E} \times E_{s t}}\right.$

(6). Based on Eq. (6) and vessel volume data from the manufacturer, the number of vessels needed to meet the desired system are calculated. Knowing the number of vessels needed and the cost per vessel, the cost model calculates the total cost and finds the pressure reservoir that results in the minimum cost. Based on the number of vessels, the cost model then adds the cost of the required piping, fittings, and valving along with the cost associated with selected motor/pump and turbine/generator. Summing up these costs, the model then once again looks for the option with the lowest total cost. As the data is different for different pressure reservoirs being studied, separate models were made for each system (pressure reservoir) type.

$$
\begin{gathered}
E_{s t}=\frac{p_{\max }\left(\frac{p_{\text {max }}}{p_{\min }}\right)^{-\frac{1}{n}}-p_{\text {min }}}{1-n} \\
V_{s t}=\frac{\text { Rated Power } \times \text { storage time }}{\eta_{R T E} \times E_{\text {st }}}
\end{gathered}
$$

As discussed above, one of the inputs into the cost model is the pressure ratio. This is the ratio of maximum to minimum pressure of the working gas in the pressure reservoir, which is the range of pressure the system operates between. As the maximum allowable operating pressures of pressure reservoirs are set input data gathered from the manufacturers, the minimum pressure can be set to any pressure. This minimum pressure is the initial air pressure the system is pre-pressurized to. To determine the optimal pressure ratio (i.e., the best minimum pressure the system should initially be pressurized to), a physics-based performance model was developed. The physics-based performance model simulates the system transient profile (i.e., liquid/gas volume, temperature, pressure behavior) and the energy stored in the system at any time. As the required storage volume in the cost model is a function of the roundtrip efficiency, the cost model benefits from interaction with the performance model.

To simulate the performance of the GLIDES system, a detailed physics-based performance model was developed. For validation, the simulation data was compared to experimental data collected from the first proof-of-concept prototype. Based on this comparison, it was found that the GLIDES system follows a Polytropic process with a constant of $\mathrm{n}=1.2$ (for compression/expansion process).

To combine the manufacturers' data, the cost model, and the physics-based performance model, an entrance model was introduced. With overall system inputs of desired storage capacity $(\mathrm{kWh})$ and an estimated value for the roundtrip efficiency, the cost model optimizes the system design for the lowest cost. The cost model outputs the selected pressure reservoir's parameters, maximum pressure, number of vessels, and total projected $\$ / k W h$ capital cost. In taking the system parameters, maximum pressure, and the number of vessels from the cost model, the physics-based performance model simulates the gas/water behavior and outputs work and power profile and an updated roundtrip efficiency based on the performance of the selected system. The overall model then outputs the total system cost, the $\$ / k W h$ cost, transient profile, and the updated roundtrip efficiency. The updated roundtrip efficiency is then fed back into the cost model to now run the calculations/optimization with an improved value for roundtrip efficiency. The system runs the loop until the lowest cost is found and a stop criterion for small change in the roundtrip efficiency is met and outputs the final values for cost, efficiency, and the transient profile. The controllable parameters in this analysis are the type of the pressure reservoirs, the system's energy capacity, hours of storage, and pressure ratio $\left(P_{\max } / P_{\min }\right)$. Therefore, to find the best pressure ratio, the $\$ / k W h$ and ED vs pressure ratio for a $100 \mathrm{~kW}$ system at various hours of storage were plotted. Based on this study, it is found a pressure ratio of $\sim 2.7$ results in the lowest $\$ / k W h$ cost and the highest ED. 


\subsubsection{Parametric Analysis}

To analyze the cost of grid-scale GLIDES at various scales from $10 \mathrm{MW}$ to $100 \mathrm{MW}$ (10 MWh to 1,000 $\mathrm{MWh}$ ), the cost of GLIDES using steel pressure vessels, carbon fiber pressure vessels, and pipe segments was analyzed in this section (keep in mind, Hornsdale battery storage is a $100 \mathrm{MW}, 129 \mathrm{MWh}$ energy storage system, Huntorf CAES is a $290 \mathrm{MW}, 580 \mathrm{MWh}$ energy storage system, and McIntosh CAES is a $110 \mathrm{MW}, 2860 \mathrm{MWh}$ energy storage system).

\subsubsection{Steel Pressure Vessels}

The cost of GLIDES using steel pressure vessels ranges from $\$ 4.61 \mathrm{E} 3 / \mathrm{kWh}$ to $\$ 4.76 \mathrm{E} 3 / \mathrm{kWh}$ for a $100 \mathrm{MW}, 10$ hours to $10 \mathrm{MW}, 1$ hour system with a 2.7 pressure ratio. The rate of change of cost with changing the storage hour is shown in Figure 23. As shown in Figure 23, with increase in system size, the system cost $(\$ / \mathrm{kWh})$ decreases. Based on this study, more than $95 \%$ of the total cost is associated with the cost of the steel pressure vessels. The high cost of the steel pressure vessels is due to their labor intensity and not commercial availability of these vessels.

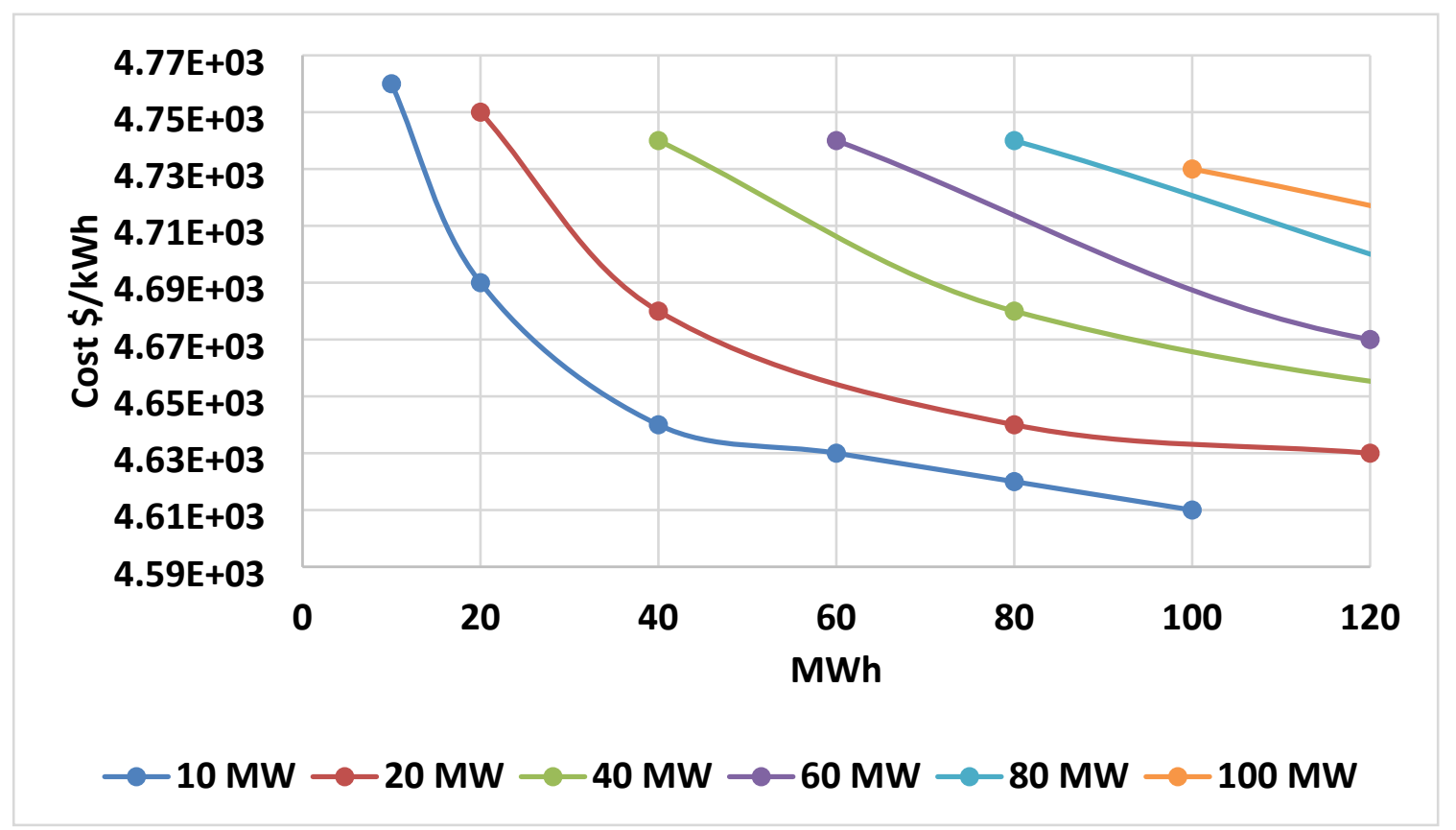

Figure 23. Cost rate of change for a grid-scale GLDIES using steel pressure vessels.

\subsubsection{Carbon Fiber Pressure Vessels}

Carbon Fiber pressure vessels are commercially available, and they are automatically made; therefore, they have a lower cost than that of steel pressure vessels. Costs as low as $\$ 736 / \mathrm{kWh}$ for a 100 MW, 10 hours system can be achieved and range up to $\$ 835 / \mathrm{kWh}$ for a $10 \mathrm{MW}, 1$ hour system as seen in Figure 24 . Based on this study around $84 \%$ of the total cost is associated with the pressure vessels. 


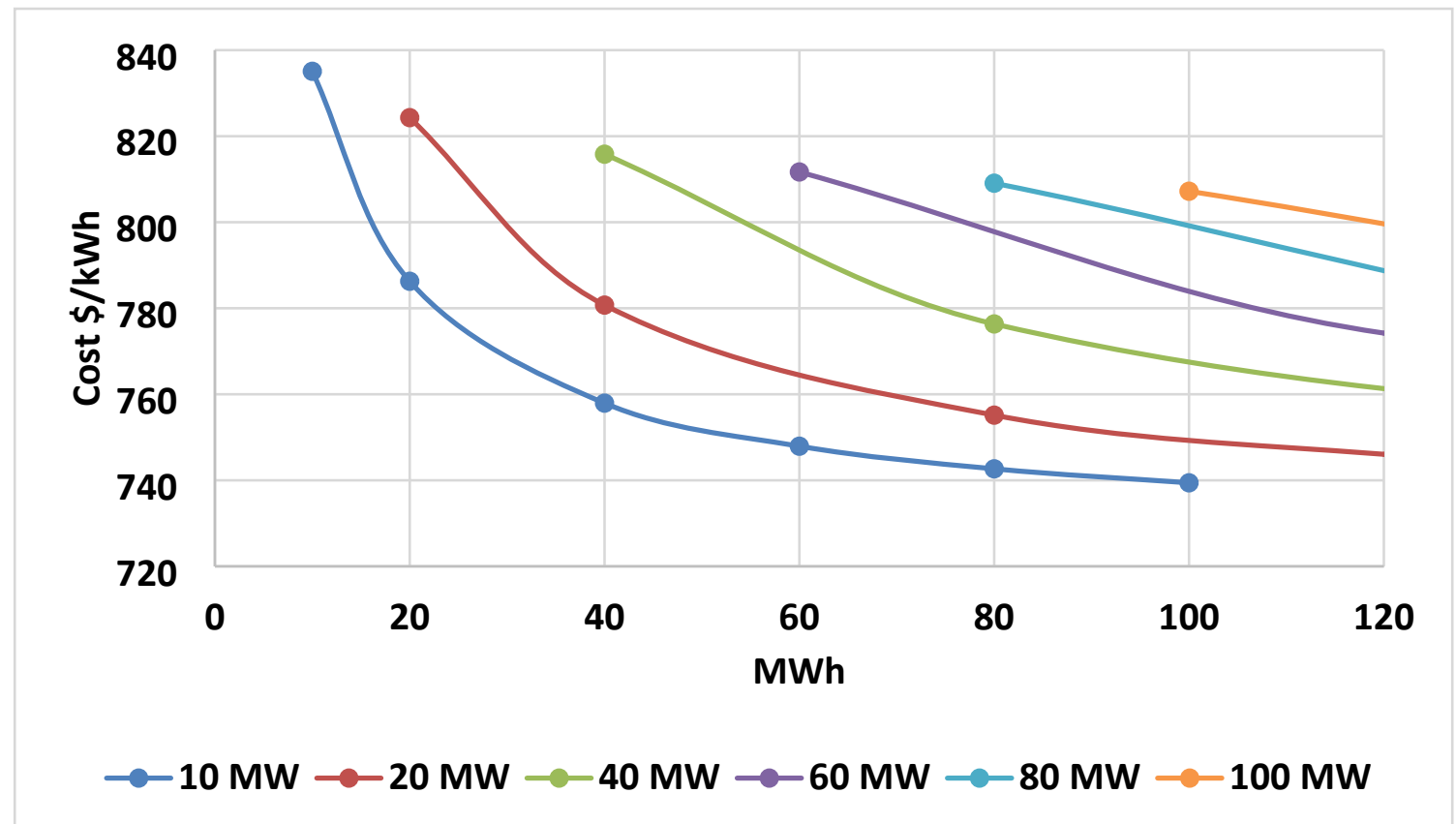

Figure 24. Cost rate of change for a grid-scale GLDIES using carbon fiber pressure vessels.

\subsubsection{High-Pressure Pipe Segments}

High-pressure pipe segments are commercially available as well and they have been widely used in gas/oil transportation. High-pressure pipe segments can be used for GLIDES and can be very cost effective. Costs as low as $\$ 262 / \mathrm{kWh}$ for a $100 \mathrm{MW}, 10$ hours system can be achieved using high-pressure pipe segments and for a smaller $10 \mathrm{MW}$, 1-hour system would go as high as $\$ 462 / \mathrm{kWh}$. High-pressure pipe segments account for around $85 \%$ of the total cost. Figure 25 shows the rate of change of cost.

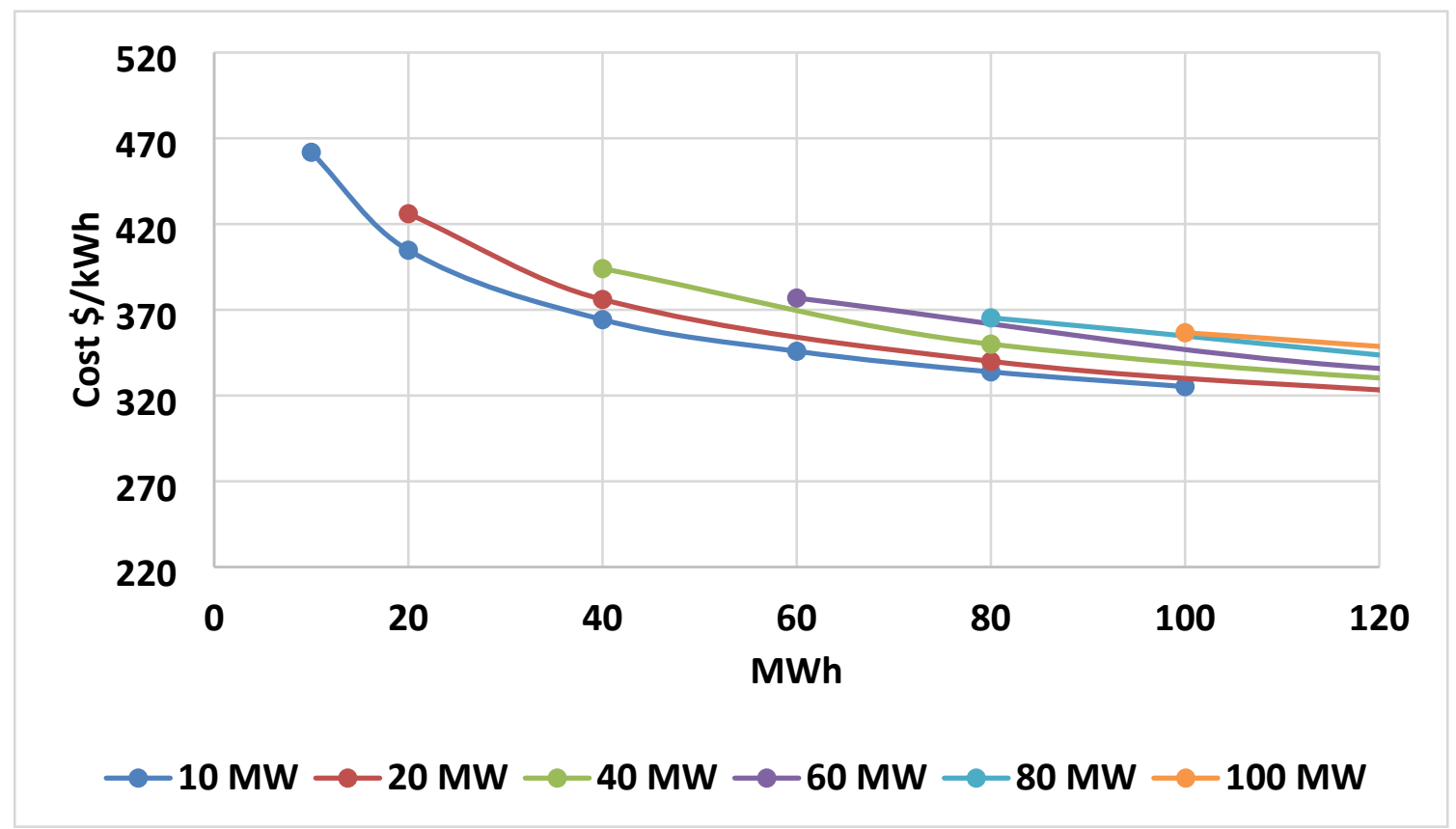

Figure 25. Cost rate of change for a grid-scale GLDIES using high-pressure pipe segments. 
As more than $80 \%$ of the system costs are due to the high cost of pressure reservoirs, other reservoirs were studied including depleted oil/gas reservoirs, aquifers, salt caverns, and abandoned pipelines with hopes to decrease storage cost. Based on the analyzed data using the models discussed in previous sections, energy storage costs as low as $\sim \$ 14 / \mathrm{kWh}$ and $\sim \$ 262 / \mathrm{kWh}$ (RTE $\sim 80 \%$ ) can be achieved for a grid-scale GLIDES using depleted oil/gas reservoirs and high-pressure pipe segments respectively. Some advantages of using underground reservoirs include large storage reservoir (grid-scale) and lower $\$ / \mathrm{kWh}$ cost; a much smaller footprint compared to above ground reservoirs. Some of the disadvantages of using underground reservoirs include scalability, geographical location with limited access to water reservoirs or renewable energy plants (e.g., if using wind energy for the charging process), and hazards, including drinking water contamination.

\subsection{ECONOMIC PERFORMANCE}

A detailed analysis of the total value proposition of the GLIDES technology in residential and commercial building applications was conducted. The primary objective of this study was to investigate the influence of implementing GLIDES module in residential and commercial buildings as an energy storage device, in conjunction with auxiliary power sources (e.g. Photovoltaics) as well as baseline electrical grid for achieving demand charge reduction and enhancing the resiliency.

Simulation of the energy systems was conducted using commercial simulation software, Hybrid Optimization of Multiple Energy Resources HOMER ${ }^{\circledR}$ Grid (version 1.7). This software package combines engineering and economics information in one comprehensive model and performs calculations to compare multiple components and design outcomes while identifying points at which different technologies become cost competitive. Three principal tasks: simulation, optimization and sensitivity analysis are performed for each system configuration to determine its technical feasibility and life-cycle cost. The simulation process determines how a particular system configuration (combination of system components of specific sizes) would behave in each configuration over a long period of time. The primary goal of the optimization process is to reduce peak power purchases from the utility by determining the best mix of resources for the least-cost solution and highest possible rate of return while considering the configurational aspects of each application layout and satisfying the technical constraints of peak power and total energy. The dispatch strategy picks the best economic option for serving the load at each time step by considering tariff, weather, and available power component in each configuration.

In this study, the key variables considered for each design configuration included:

- Capacity and associated cost of individual GLIDES module

- Electricity tariff structure

- Electric load profile

- Size of PV power generation and corresponding solar global horizontal irradiance (GHI)

- Incentives

- Demand load relief programs (Demand response DR incentive)

- Cost variances for sensitivity analysis

The key performance and economic metrics that were investigated in detail, for each of these applications are listed below:

- Utility bill savings

- Annual Carbon dioxide emissions reductions

- Levelized cost of energy (LCOE)

- Net present cost (NPC)

- Return on investment (ROI)

- Payback period

- Electric utility purchases 
These operational variables and resulting economic and performance metrics were investigated for both residential and commercial buildings. Six different regions in the USA were considered: Tennessee, Massachusetts, Florida, California, Washington, and Hawaii, representing different climate regions and tariff structures. Storage modules of capacity of $0.5 \mathrm{kWh}-15 \mathrm{kWh}$ were considered for residential buildings, whereas modules of $25 \mathrm{kWh}-500 \mathrm{kWh}$ of storage capacity were considered for commercial buildings. Additionally, case studies for five different commercial buildings, viz. full-service restaurant, supermarket, small office, medium sized hotel, and small strip mall were also performed.

\subsubsection{Residential Buildings}

The influence of energy storage capacity of GLIDES on annual utility bill savings in residential buildings in six different regions across the country were analyzed. Because of the lack of demand charges in residential tariffs, coupled with $20 \%$ loss of energy after each charge - discharge cycle, GLIDES alone cannot yield any savings. However, utilization of renewable energy (PV) can help offset some of the utility bills while also decreasing the peak energy demand. As a result, GLIDES configurations including a $3 \mathrm{~kW}$ PV system were analyzed for their utility bill savings potential without any DR incentive. As shown in Figure 26, higher utility bill savings are achievable in Boston (Massachusetts), Los Angeles (California), and Hawaii compared to Oak Ridge (Tennessee), Florida and Seattle (Washington). The utility bill savings are driven by the tariff rates. A comparative analysis of the utility bill savings across these six regions was repeated by considering the DLRP incentive Figure 26. Higher annual savings in the range of $\$ 900$ - \$1,000 can be achieved (not shown) in Boston, Los Angeles, and Hawaii when DR incentives are implemented.

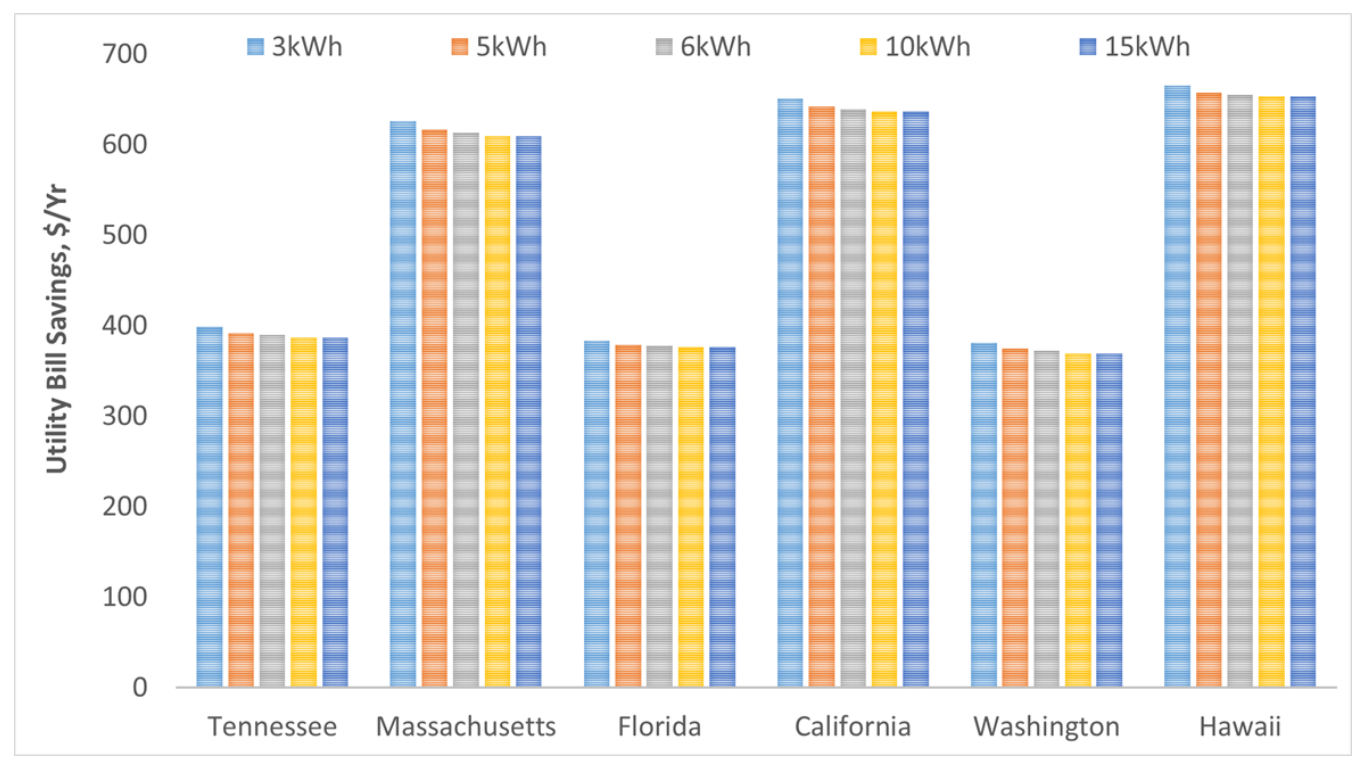

Figure 26: Comparison of utility bill savings across six different regions for five different GLIDES capacity ratings in a hybrid configuration with $3 \mathrm{~kW}$ PV. No DR incentive.

\subsubsection{Commercial Buildings}

Utilization of GLIDES as an energy storage module in commercial buildings was investigated with different hybrid configurations. Energy storage capacities in the range of $25 \mathrm{kWh}$ to $500 \mathrm{kWh}$ were considered and analyzed with and without auxiliary PV and DR incentive (DLRP). Additionally, two or more commercial electricity tariff structures were also applied as the commercial rate codes differ significantly based on the peak and maximum energy demand. Commercial buildings' energy demand 
also differs significantly, ranging from $300 \mathrm{kWh}-3500 \mathrm{kWh} /$ day, hence, a wide range of configurations were studied. The value proposition of GLIDES energy storage configuration was repeated for commercial buildings representing different electricity tariff rate structures across the USA, as shown in Figure 27. Generic commercial building load profile consuming $3500 \mathrm{kWh} /$ day was analyzed with a 300 $\mathrm{kWh}$ GLIDES module. Considering the DR incentive for all six regions examined, annual utility bill savings varied from $\$ 14,000$ to $\$ 60,000$ with a standalone $500 \mathrm{kWh}$ GLIDES with no PV configuration and from $\$ 70,000$ to $\$ 140,000$ in a hybrid $300-\mathrm{kW}$ PV plus $300-\mathrm{kWh}$ GLIDES configuration. A more useful representation of these savings is compared for individual configurations and shown as ROI and annual utility bill savings in

Figure 27. ROI for the 300-kWh configuration varies from 3-12\% with PV and no DR incentive and 0$16 \%$ without PV nor DR incentive.
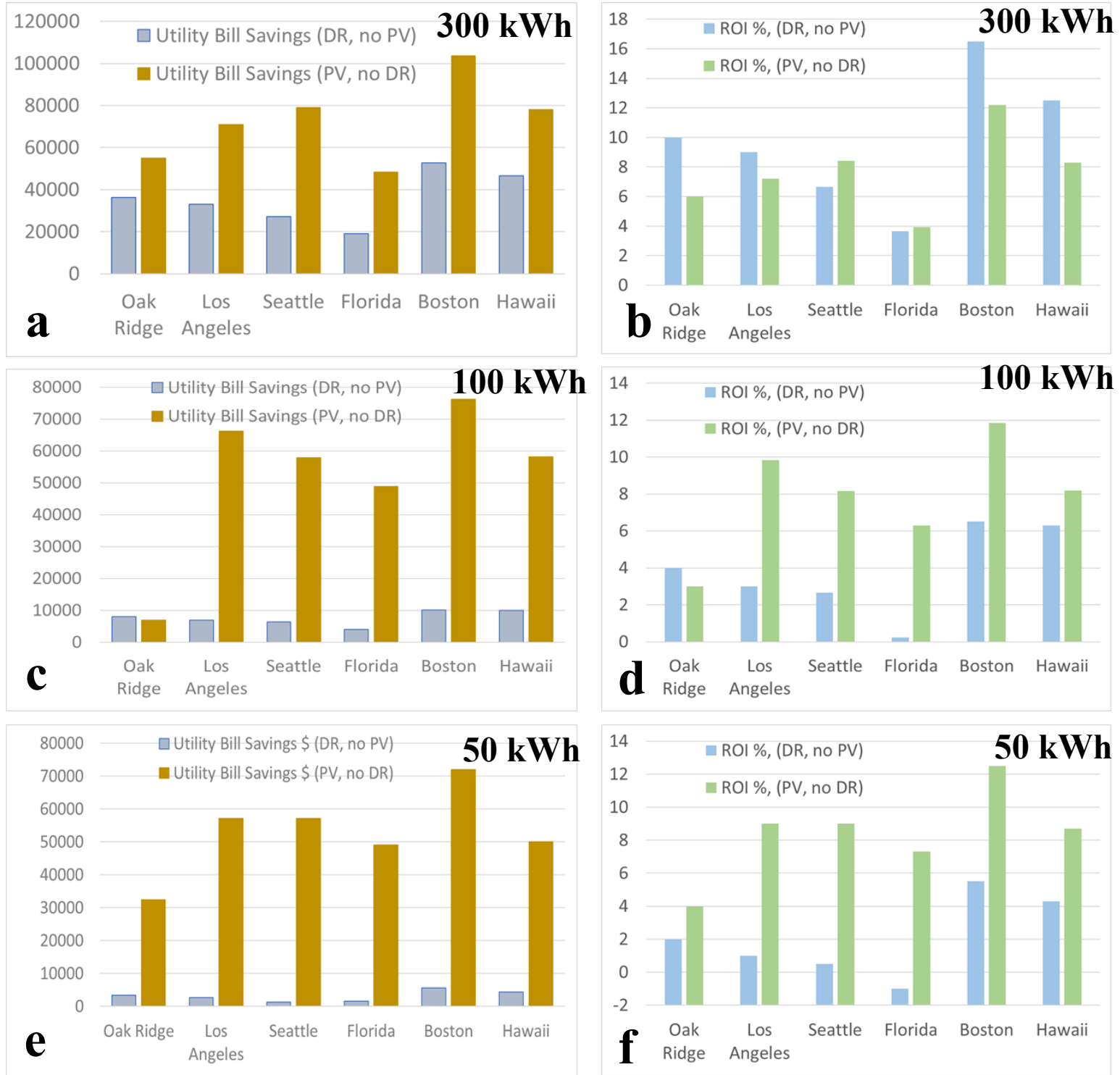

Figure 27: ROI and Utility bill savings across 6 different regions: Influence of capacitance, PV, DR. (a \& b) - 300 kWh; $(c \& d)-100 \mathrm{kWh} ;($ \&\&f $)-50 \mathrm{kWh}$ 


\subsubsection{Key findings}

Based on the detailed cost and performance analysis of the GLIDES module as resource in lowering the peak energy demand and corresponding utility bills, the following conclusions were deduced:

1. At the current estimated costs of GLIDES, residential applications require auxiliary PV and DR incentives to yield acceptable ROI.

2. GLIDES energy storage module offers higher net annual value in a commercial building than a residential building, driven by higher CapEx costs

3. Target costs of $<\$ 1,300 / \mathrm{kWh}$ for GLIDES and $\$ 1.5 /$ Watt for installed PV are required to yield an ROI $>9 \%$ in a residential building application

4. Annual utility bill savings of $\$ 400$ - $\$ 800$ is possible in a residential building with different GLIDES based configurations, irrespective of the region/tariff structure

5. Of all the residential areas considered in this analysis, installation of GLIDES is more favorable in New England area, California, Hawaii followed by Tennessee, Florida, and Washington

6. Addition of PV in a commercial building generally decreases the ROI compared to the GLIDES module without PV, due to higher installed PV costs

7. Annual utility bill savings can reach up to $\$ 60,000$ without $P V$ and up to $\$ 140,000$ with $P V$, in a commercial building with an energy demand of $3500 \mathrm{kWh} /$ day

8. Demand response incentives such as Demand Load Relief Program increases the overall value proposition in any building

9. Current GLIDES CapEx costs can already yield $>6 \%$ ROI in most of the regions analyzed, reaching a highest value of $16 \%$ in the New England area.

10. GLIDES modules offer highest value in a commercial building in New England area, Tennessee, Hawaii followed by California, Washington, and Florida

11. The following GLIDES based configurations are suitable for applications in different commercial buildings (Table 1, Figure 28), as suggested by the ROI analysis.

Table 1: Best GLIDES module-based configuration suitable for different buildings, based on highest ROI

\begin{tabular}{|l|l|l|}
\hline Building Type & GLIDES & GLIDES + PV \\
\hline Residential & $3 \mathrm{kWh}$ & $3 \mathrm{kWh}+3 \mathrm{~kW} \mathrm{PV}$ \\
\hline Full-Service Restaurant & $25 \mathrm{kWh}$ & $25 \mathrm{kWh}+50 \mathrm{~kW} \mathrm{PV}$ \\
\hline Supermarket & $300 \mathrm{kWh}$ & $25 \mathrm{kWh}+50 \mathrm{~kW} \mathrm{PV}$ \\
\hline Small Office & $25 \mathrm{kWh}$ & $25 \mathrm{kWh}+50 \mathrm{~kW} \mathrm{PV}$ \\
\hline Medium Hotel & $100 \mathrm{kWh}$ & $100 \mathrm{kWh}+50 \mathrm{~kW} \mathrm{PV}$ \\
\hline Small Strip Mall & $25 \mathrm{kWh}$ & $25 \mathrm{kWh}+50 \mathrm{~kW} \mathrm{PV}$ \\
\hline
\end{tabular}




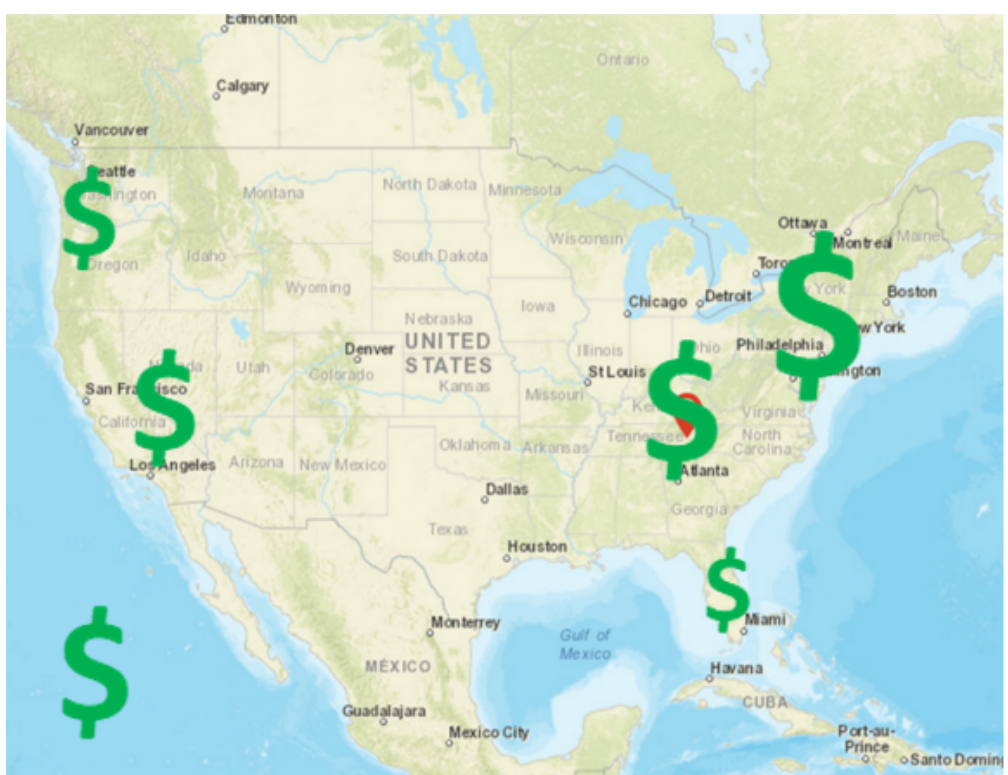

Figure 28: Relative utility bill savings in commercial buildings across the USA.

\section{CONCLUSION}

The project aimed to raise the market readiness of GLIDES through system design, performance improvements and technoeconomic analysis to identify favorable configurations of GLIDES and quantify its value proposition. Spray-cooling during charging proved to improve GLIDES energy density by $12 \%$ and lower the first cost per $\mathrm{kWh}$ of GLIDES by $11 \%$. A load-following control system was designed to interface GLIDES to the grid. The technoeconomic analysis showed that GLIDES coupled with solar photovoltaic generation achieves between $\$ 400$ and $\$ 800$ in utility bill savings in residential homes and up to $\$ 140,000$ in commercial building with electric energy consumption of $3500 \mathrm{kWh} /$ day. The analysis determined the optimal configuration of GLIDES storage capacity and PV rated power for maximum annual electric utility bill saving. 